NBER WORKING PAPER SERIES

\title{
ASSET PRICING LESSONS FOR MODELING BUSINESS CYCLES
}

Michele Boldrin

Lawrence J. Christiano

Jonas D.M. Fisher

Working Paper 5262

\section{NATIONAL BUREAU OF ECONOMIC RESEARCH 1050 Massachusetts Avenue \\ Cambridge, MA 02138 \\ September 1995}

We are grateful to V.V. Chari, John Cochrane, Martin Eichenbaum, Zvi Hercowitz, Larry Jones, Albert Marcet, David Marshall and Serena Ng for comments. Boldrin thanks the Fundación Marc Rich, Christiano thanks the National Science Foundation, and Fisher thanks the SSHRC for financial support. This paper is part of NBER's research program in Asset Pricing and Economic Fluctuations. Any opinions expressed are those of the authors and not those of the National Bureau of Economic Research.

() 1995 by Michele Boldrin, Lawrence J. Christiano and Jonas Fisher. All rights reserved. Short sections of text, not to exceed two paragraphs, may be quoted without explicit permission provided that full credit, including $\odot$ notice, is given to the source. 


\title{
ASSET PRICING LESSONS FOR MODELING BUSINESS CYCLES
}

\begin{abstract}
We develop a model which accounts for the observed equity premium and average risk free rate, without implying counterfactually high risk aversion. The model also does well in accounting for business cycle phenomena. With respect to the conventional measures of business cycle volatility and comovement with output, the model does roughly as well as the standard business cycle model. On two other dimensions, the model's business cycle implications are actually improved. Its enhanced internal propagation allows it to account for the fact that there is positive persistence in output growth, and the model also provides a resolution to the "excess sensitivity puzzle" for consumption and income. Key features of the model are habit persistence preferences, and a multisector technology with limited intersectoral mobility of factors of production.
\end{abstract}

Michele Boldrin Departmento de Economia Universidad Carlos III Madrid, Spain
Lawrence J. Christiano
Jonas Fisher
Department of Economics
Northwestern University
2003 Sheridan Road
Evanston, IL 60208-2600
and NBER
Department of Economics
Social Science Center
University of Western Ontario
London, Ontario N6A 5C2
CANADA 


\section{Introduction}

General equilibrium models with complete markets and optimizing agents have enjoyed a measure of success in accounting for business cycle fluctuations in quantities. However, these models have been notoriously unsuccessful in accounting for the behavior of asset prices. ${ }^{1}$ Two failures in particular have attracted the most attention: the equity premium puzzle, the fact that returns on the stock market exceed the return on Treasury bills by an average of 6 percentage points; and the risk free rate puzzle, the fact that Treasury bills on average earn a very low return. For the most part, the response of business cycle researchers has been to ignore the asset pricing implications of their models.

This is unfortunate. As emphasized most recently by Cochrane and Hansen (1992), business cycle models assume that households equate intertemporal marginal rates of substitution in utility with intertemporal marginal rates of transformation. Under the complete markets hypothesis, asset returns offer a direct measure on these margins, and so should provide an excellent guide to constructing and evaluating business cycle models.

This is the perspective adopted here. ${ }^{2}$ We take the standard business cycle model as our starting point, and modify it by replacing the power specification of utility with the habit persistence specification proposed by Constantinides (1990). ${ }^{3}$ There are two reasons that we do this. First, as demonstrated by Constantinides, habit persistence has the potential to account for both asset return puzzles while implying only a modest degree of risk aversion on the part of households. Alternatives, for example, Abel's (1990) 'keeping up with the Jones' specification, power utility and non-expected utility, in practice require high risk aversion to account for the asset pricing puzzles. ${ }^{4}$ Throughout our analysis, we restrict

\footnotetext{
${ }^{1}$ Influential early discussions of this include Hall $(1978)$, Hansen and Singleton $(1982,1983)$ and Mehra and Prescott (1985).

${ }^{2}$ Since starting on this work, we have become aware of independent research along similar lines. This includes the work of Danthine and Donaldson (1994), Jermann (1994), Lettau and Uhlig (1995) and Tallarini (1995). Among these papers, only Jermann considers habit persistence preferences. Below, we discuss the similarities and differences between our papers.

${ }^{3}$ Other researchers have investigated a different set of perturbations to the complete markets model. See, for example, Nason (1988), Reitz (1988) and Tsionas (1994). Some have followed the suggestion of Mehra and Prescott (1985) by investigating the potential of market incompleteness to account for the equity premium and risk free rate. See, e.g., Aiyagari and Gertler (1992), Danthine, Donaldson and Mehra (1992), Heaton and Lucas (1992), Mankiw (1986) and Weil (1992).

${ }^{4}$ The analyses we have in mind here are based on pure exchange economies in which the equilibrium con-
} 
the parameterization of habit persistence so that the coefficient of relative risk aversion averages roughly unity. Our second reason for studying habit persistence preferences is that, according to several econometric analyses, this form of preferences can reconcile US data on consumption and asset returns (see Burnside (1994), Ferson and Constantinides (1991) and Heaton (1995).)

We show that introducing habit persistence preferences into the standard business cycle model has no impact on the equity premium. After diagnosing the reasons for this, we address the following questions:

- How must the technology in this model be modified to account for the mean risk free rate and equity premium?

- What are the business cycle implications of the resulting model?

We develop a model which accounts for the equity premium and average risk free rate. Our model's ability to account for the equity premium lies in producing the right business cycle pattern in the price of capital. To generate this pattern, we adopt - in addition to habit persistence - a multisectoral technology with limited intersectoral mobility of factors of production.

Our model's successes in accounting for asset pricing phenomena do not come at the expense of its business cycle implications. With respect to the conventional measures of business cycle volatility and comovement with output, the model does roughly as well as the standard business cycle model. On two other dimensions, the model actually outperforms the standard model. First, the dynamics in our model enhance its internal propagation of shocks, improving its ability to account for the observed persistence in output growth. Second, our model accounts for the so-called excess sensitivity puzzle: instrumental variables

sumption process is specified exogenously. The 'keeping-up-with-the-Jones' and nonexpected utility specifcations studied by Campbell and Cochrane $(1995)$, and Weil $(1989,1992)$ use risk aversion in excess of 40 . To simultaneously drive the risk free rate below its empirical value and the equity premium above its empirical value in the Mehra and Prescott (1985) model requires risk aversion in excess of 30 (see section 3 below). For recent evidence which suggests that levels of risk aversion this high are empirically implausible, see Barsky, Juster, Kimball and Shapiro (1995). By resorting to non-standard distributions for the equilibrium consumption process, it is possible to account for the asset pricing puzzles with power utility and lower risk aversion. See, for example, Kandel and Stambaugh $(1990,1991)$, Reitz (1988) and Tsionas (1994). 
regressions indicate consumption growth is strongly related to income, and relatively weakly related to interest rates (Campbell and Mankiw $(1989,1991)$ and Hall (1988).) While this puzzle is an embarrassment for the standard business cycle model, it is not a problem for ours.

The following section provides a brief, nontechnical overview of our paper and the main results. After that comes the formal analysis, followed by concluding remarks.

\section{Overview of the Analysis}

Our analysis begins with a version of the pure exchange economy studied in Lucas (1978) and Mehra and Prescott (1985). We use this to establish a benchmark and to identify the key channels by which changes in preferences impact on the equity premium and the risk free rate. The insights obtained here are then applied to business cycle modeling. The following two subsections summarize our basic results for the exchange economy and for business cycle models, respectively.

\subsection{Overview of Findings for the Exchange Economy}

Consistent with the results in Constantinides (1990), we show that habit persistence with low risk aversion can account for both the equity premium and risk free rate puzzles in an exchange economy. Here, we review our results with respect to the equity premium.

It is useful to recall a classic covariance formula: the equity premium is negatively related to the conditional covariance between the one-period-ahead marginal utility of consumption and the rate of return on equity. A change in the specification of the model changes both arguments in the covariance term. Thus, when we switch from power utility to habit persistence there are two effects which raise the equity premium. On the one hand, it increases the spread, across states of nature, of the one-period-ahead marginal utility of consumption. Holding other things constant, this raises the equity premium. We refer to this mechanism as the curvature channel, because it is determined by the degree of curvature in the utility function. On the other hand, the type of consumption smoothing motive inherent in habit persistence gives rise to a particular pattern of demand for assets across states of nature: 
when consumption opportunities are high, households seek to buy assets, and when consumption opportunities are low, they seek to sell. Because the stock of physical capital is fixed in the exchange economy, variation in the demand for equity translates into large fluctuations in the price of capital across states of nature, with large capital gains in states when consumption is high, and small or negative capital gains when consumption is low. Holding other things constant, this also raises the equity premium. We refer to this as the capital gains channel.

The curvature channel is the exclusive focus of much of the empirical literature on the equity premium (we have in mind here the work stimulated by Hansen and Singleton $(1982,1983)$.) It takes the empirical process for consumption and the rates of return as given and evaluates alternative specifications of utility for their ability to reconcile the two. In analyses of general equilibrium economies the rate of return on equity is endogenous, and so the capital gains channel also plays a role.

There are two reasons why this channel warrants considerable attention. First, in all of our computational experiments, the capital gains channel plays by far the most important role quantitatively. Second, because the price of capital reflects the outlook for events extending into the distant future, it is influenced by many other features of the environment in addition to the curvature properties of the utility function. (We measure curvature by the elasticity of the marginal utility of consumption with respect to consumption.) These features include such things as households' preferences over the intertemporal pattern of consumption, and the persistence properties of households' consumption opportunities. Thus, although our computational experiments suggest that high curvature is a necessary ingredient for getting the equity premium, it is by no means sufficient. We dramatize this point by discussing examples in which there is high curvature, yet the equity premium is negative.

These considerations suggest that the following two ingredients are crucial for a general equilibrium model to generate an equity premium: (i) households must have a strong incentive to buy assets when the marginal utility of consumption is low, and to sell assets when the marginal utility of consumption is high; and (ii) a technology which frustrates these desires. The ability of the exchange economy to account for asset returns in part reflects the extreme position it takes on (ii): capital supply is completely inelastic and labor supply 
cannot be varied to offset the consumption impact of unfavorable shocks.

\subsection{Overview of Findings for Modeling Business Cycles}

Armed with this intuition, we proceed to analyze the introduction of habit persistence into the standard real business cycle model. As noted previously, we find that this modification has essentially no impact on the equity premium. But, this is not surprising, in view of the intuition developed above. The real business cycle model in effect assumes that the supply of capital is infinitely elastic, so that its equilibrium price is a constant. As is well known, the payoff on capital (its rental rate) in the standard business cycle model fluctuates very little. As a result, fixing the price of capital essentially shuts down the capital gains channel. The curvature channel is more complicated in the production economy, because of the endogeneity of consumption. ${ }^{5}$ Still, it plays a negligible quantitative role.

Our interpretation of the absence of an equity premium in this model is that households have an unrealistically large number of opportunities to smooth consumption. These reflect their ability to flexibly exploit three margins: variations in labor effort, variations in the rate of capital accumulation, and variations in the allocation of factors of production to producing consumption and investment goods. We proceed to study a multisector production model in which households have less flexibility.

For our first modification, we assume that capital and consumption are non-homogeneous goods, and that capital inputs must be assigned to the production of the two goods in advance of the realization of the current period technology shock. We assume, for example, that an oven used to bake bread cannot be instantaneously transformed into a bulldozer. Introducing this form of ex post inflexibility converts the model into a two-sector model. Because there are diminishing returns in varying the labor input, this places curvature in the production transformation frontier between consumption and investment goods, making the supply of capital less than infinitely elastic. This change has a positive impact on the model's equity premium, though it does not get it even close to its empirically observed value.

\footnotetext{
${ }^{5}$ For example, in the context of the exchange economy, only events during the life of the one-period equity claim play a role in the curvature channel, because equilibrium consumption is exogenous. In a business cycle model consumption is influenced in part by views about the future, and so the future plays a role in the curvature channel too.
} 
Next, we assume that the sectoral labor inputs also have to be chosen a period in advance, before the technology shock is realized. This assumption captures the various real-world factors that make finding work or changing jobs a time-consuming process. As a result of these assumptions, capital supply is completely inelastic in the period of a shock. ${ }^{6}$ At least in the short run, the model resembles the exchange economy in that there are no opportunities to insulate consumption contemporaneously from shocks. The cumulative effect of these modifications is to raise the equity premium to 2 percent.

Finally, we introduce an amount of leverage suggested by the empirical analysis in Benninga and Protopapadakis (1990). When we do so the equity premium jumps to around 5 percent. At the same time, the risk free rate is 2.7 percent. Based on the statistical information provided in Cecchetti, Lam and Mark (1993), we argue that these values are not significantly different from their empirical counterparts.

The last step in our analysis is to study the business cycle implications of this model. We find that they are surprisingly good. Where the model does poorly, it does not do substantially worse than the standard business cycle model. On the plus side, the shortterm rigidities in our model and its multisectoral structure enhance its internal propagation by delaying the full response of factors of production to shocks. Habit persistence also plays a role here. For example, when a shock generates a positive innovation in consumption, habit persistence creates an incentive to apply factors of production in such a way as to keep consumption high for several periods. ${ }^{7}$

Our model's ability to resolve the excess sensitivity of consumption growth to income reflects that, under habit persistence, the intertemporal Euler equation relates consumption

\footnotetext{
${ }^{6}$ See Goolsbee (1995) for empirical evidence that short run capital supply is very inelastic.

${ }^{7}$ Among the papers mentioned in the introduction that are related to ours, the closest is that of Jermann (1994) who also studies habit persistence preferences. Still, his paper differs in many respects from ours. For example, the version of Jermann's model that incorporates habit persistence holds aggregate labor effort constant, while the intersectoral allocation of capital and labor are free to respond to shocks. Consistent with the analysis here, Jermann finds that capital supply must be less than perfectly elastic if he is to get an equity premium. Unlike here, his strategy for reducing this elasticity is to impose adjustment costs on the installation of new capital. One important difference in the two papers lies in the interpretation of the results: Jermann does not emphasize the capital gains channel in analyzing the impact of changing preferences on the equity premium, whereas we stress its central role. Finally, there is a difference in focus between the two papers. Ours focuses relatively more on the business cycle implications the model, while Jermann focuses on a broader set of asset pricing implications.
} 
growth to lagged consumption growth, as well as to expectations of future consumption growth. In this case, the apparent excess sensitivity to income reflects income's statistical role as a proxy for these variables. The model's ability to account for the lack of sensitivity of consumption growth to interest rates is perhaps not surprising, in view of the fact that our assumption of high curvature is equivalent to the assumption of low intertemporal substitution in consumption. Because agents in our model have low risk aversion, our framework provides a formal basis for Hall's (1988) suggestion that the weak empirical relation between consumption growth and the interest rate should be interpreted as reflecting low intertemporal substitution in consumption and not high risk aversion.

\section{The Exchange Economy}

In this section we analyze versions of the exchange economy studied in Lucas (1978) and Mehra and Prescott (1985). We accomplish the following three objectives. First, we describe the model economy, set up the notation and market decentralization used throughout the paper, and document that the model is consistent with the observed mean risk free rate and equity premium. Second, we review some key properties of habit persistence preferences, and compare them with power utility and the 'keeping up with the Jones' preferences recently studied by Abel (1990), Campbell and Cochrane (1995), and Lettau and Uhlig (1995). Third, we present experiments designed to shed light on the channels by which changes in preferences affect the risk-free rate and equity premium in equilibrium. Our primary result is that the main channel by which a change in preferences impacts on the equity premium is the capital gains channel discussed in the previous section.

\subsection{The Model Economy}

\section{Households}

The economy is composed of a continuum of infinitely lived, identical households who maximize expected discounted utility. Let $\mathcal{E}_{t}$ denote the expectation operator conditional on the information available at time $t$. At every date, $t$, the representative household values 
consumption henceforth according to: ${ }^{8}$

$$
\mathcal{E}_{t} \sum_{j=t}^{\infty} \beta^{j-t} \frac{\left(C_{j}-X_{j}\right)^{1-\phi}-1}{1-\phi}
$$

where $X_{j}$ represents the habit stock, which evolves as follows:

$$
X_{j}=h X_{j-1}+b C_{j-1}
$$

In (3.1), $0<\beta<1$ is the household's discount factor. For the purposes of our analysis, we define power utility preferences as the case $\phi>0, h=b=0$, and habit-persistence preferences as the case $\phi \equiv 1$, and either $h$ or $b \neq 0$.

At every date, $t$, the household must satisfy the following budget constraint:

$$
B_{t}+S_{t}+C_{t} \leq\left(1+r_{t}^{e}\right) S_{t-1}+\left(1+r_{t-1}^{f}\right) B_{t-1}
$$

where $B_{t}$ and $S_{t}$ denote period $t$ acquisition of two types of one-period assets, denominated in consumption units. Their rates of return are $1+r_{t}^{f}$ and $1+r_{t+1}^{e}$, respectively. The rate of return on $S_{t}$ is conditional on the realization of the date $t+1$ state of nature and the rate of return on $B_{t}$ is not. The problem of the household is as follows: at every date $t$, it takes $S_{t-1}, B_{t-1}, X_{t}$ and $\left\{r_{j}^{e}, r_{j-1}^{f} ; j \geq t\right\}$ as given and maximizes (3.1) subject to (3.2), (3.3) by choice of $\left\{B_{j}, S_{j}, C_{j} ; j \geq t\right\}$.

\section{Firms}

The technology for converting capital, $K_{t}$, into output, $Y_{t}$, is as follows:

$$
Y_{t}=Z_{t} K_{t}
$$

\footnotetext{
${ }^{8}$ This (standard) specification of the habit persistence utility function has the distinctive feature that the present discounted value of the utility of a consumption sequence is non-monotone in any particular period's consumption. This reflects the fact that, although the period utility function is increasing in current consumption, period utility at later dates is decreasing in current consumption. This latter effect dominates at high values of consumption. In the simulations computed for this paper, consumption is always in the region of increasing marginal utility.
} 
where

$$
Z_{t}=Z_{t-1} \exp \left(\theta_{t}\right)
$$

The random variable $\theta_{t}$ follows the autoregressive process

$$
\theta_{t}=(1-\rho) \bar{\theta}+\rho \theta_{t-1}+\epsilon_{t}
$$

and $\epsilon_{t} \sim N\left(0, \sigma^{2}\right)$, for all $t \geq 0$. Capital does not depreciate, and there exists no technology for increasing or decreasing its magnitude. The aggregate, per capita stock of capital is a constant, equal to $K>0$.

We assume firms have a one period planning horizon. In order to operate capital in period $t+1$, a firm must purchase it in period $t$. To do so, it issues equity $S_{t}$, subject to the following financing constraint:

$$
P_{k, t} K_{t+1} \leq S_{t}
$$

where $P_{k, t}$ is the date $t$ price of capital, denominated in consumption units and $K_{t+1}$ represents the quantity of capital the firm plans to use. Let $\pi_{t+1}$ denote the firm's period $t+1$ revenues net of expenses, denominated in period $t+1$ consumption units. Revenues include the sale of output, $Y_{t+1}$, plus the sale of the capital stock, $P_{k, t+1} K_{t+1}$. The firm's expenses are limited to its obligations on equity, $\left(1+r_{t+1}^{e}\right) S_{t}$. Its choice variables are $S_{t}$ and $K_{t+1}$ and it takes $P_{k, t}$, and the state contingent objects, $r_{t+1}^{e}$ and $P_{k, t+1}$, as given. The firm's outlays in each state of the world must not exceed its revenues:

$$
\pi_{t+1}=Y_{t+1}+P_{k t+1} K_{t+1}-\left(1+r_{t+1}^{e}\right) S_{t} \geq 0
$$

The firm's problem at date $t$ is to maximize, by choice of $S_{t}$ and $K_{t+1}$, the value of $\pi_{t+1}$ across states of the world, subject to (3.4)-(3.8). This implies that the financing constraint, (3.7), is satisfied as a strict equality in equilibrium. Linear homogeneity of the firm's objective, together with the weak inequality in (3.8), imply the equilibrium condition, $\pi_{t+1}=0$ for all $t+1$, and for all states of nature, so that:

$$
1+r_{t+1}^{e}=\frac{Z_{t+1}+P_{k, t+1}}{P_{k, t}}
$$




\section{Equilibrium}

We adopt the normalization that the number of households and firms is one. Then, the resource constraints for this economy can be expressed as follows:

$$
C_{t} \leq Y_{t}, K_{t} \leq K
$$

A sequence-of-markets competitive equilibrium is defined in the usual way.

The objects in equilibrium are obtained as follows. First, $C_{t}=Z_{t} K$. We find prices by combining the household's first order condition for $S_{t}$ with (3.5) and (3.9) to get:

$$
p_{k, t}=\mathcal{E}_{t} p_{c, t+1} \exp \left(\theta_{t+1}\right)\left[1+p_{k, t+1}\right]
$$

where $p_{k, t} \equiv P_{k, t} / Z_{t}$. In addition,

$$
p_{c, t+1}=\beta \frac{\Lambda_{c, t+1}}{\Lambda_{c, t}}
$$

where $\Lambda_{c, t}$ denotes the derivative of (3.1) with respect to $C_{t}$. This is computable given the solution for $C_{t}$ described above. We then find $p_{k, t}$ by specifying it to be a function of $\theta_{t}$ and solving for the fixed point of the functional equation, (3.11). To approximate the solution to this and other functional equations, we use the nonlinear methods described in Judd (1992) and Christiano and Fisher (1994). Given $P_{k, t}=p_{k, t} Z_{t}$, we solve for $r_{t+1}^{e}$ using (3.9). Finally,

$$
1+r_{t}^{f}=\frac{1}{\mathcal{E}_{t} p_{c, t+1}}
$$

\subsection{Preferences and Asset Returns}

Here, we review key properties of habit persistence preferences that are relevant for asset prices. We also discuss the implications of habit persistence for the risk free rate, and present our formal decomposition of the equity premium into curvature and capital gains channels.

\section{Risk Aversion and Curvature}


To understand the impact of habit persistence on the equity premium, it is important to distinguish the concept of relative risk aversion $(R R A)$ from measures of the curvature of the utility function. The concept of curvature we use is $-C \Lambda_{c c} / \Lambda_{c}$, where $\Lambda_{c c}$ is the derivative of $\Lambda_{c}$ with respect to $C$, and absence of a time subscript indicates the value in nonstochastic steady state. With preferences like power utility, or 'keeping up with the Jones', curvature and risk aversion are identical. This is why researchers who seek to account for the equity premium by increasing curvature, simultaneously encounter counterfactually high levels of risk aversion. Constantinides (1990) pointed out that, in contrast, habit persistence preferences disentangle these two concepts. For example, for $\beta$ close to $1, R R A$ is close to unity, independent of $b$ and $h$. At the same time, by increasing the values of these parameters, curvature - and the equity premium - are both raised. (See the Appendix for a further discussion.)

To gain intuition into why curvature can be high while $R R A$ is low under habit persistence, recall the definition of $R R A$ : it measures how much an individual household is willing to pay to avoid a fair bet on its wealth. This magnitude is directly related to the utility loss the household suffers in the adverse state of the world. If the household were forced to accept an immediate drop in consumption, the loss of such a bet would be very painful, given the short-term exogeneity of the habit stock and the assumed high curvature. However, the habit persistence household can avoid this. Though the present value of its total lifetime consumption must fall, recourse to credit markets enables the household to slow the fall in actual consumption so that the habit stock can fall. This is why the disutility occasioned by the loss of a bet on wealth may be relatively small for a household with habit persistence preferences.

It is revealing to compare the implications for risk aversion of habit persistence with those of 'keeping up with the Jones' preferences. For the latter type of household, the habit stock is exogenous for all time, and so recourse to credit markets represents a much less effective cushion against the loss of a bet. As a result, the level of risk aversion implied by this utility function is very high. For example, in the formulation studied by Campbell and Cochrane (1995), risk aversion is 48 (see also Weil (1992).) This contrasts with risk aversion of roughly unity for the habit persistence preferences studied in this paper. 


\section{The Risk Free Rate}

Consider (3.13) along a nonstochastic steady-state growth path in which $C_{t}=C_{t-1} \exp (\bar{\theta})$ :

$$
1+r_{t}^{f}=\left\{\begin{array}{c}
\frac{\exp (\phi \bar{\theta})}{\beta}, \text { for power utility } \\
\frac{\exp (\bar{\theta})}{\beta}, \text { for habit persistence. }
\end{array}\right.
$$

As is well-known, the elasticity of intertemporal substitution in consumption is the inverse of our measure of curvature. In the appendix, we show that with habit persistence utility, intertemporal substitution is reduced by increasing $b$ or $h$. Also it is well-known that raising $\phi$ reduces intertemporal substitution in consumption in the case of power utility function. Thus, we infer from (3.14) that reducing intertemporal substitution has a very different impact on the risk free rate, depending on whether one adopts habit persistence or power preferences.

The intuition for this difference between the two utility functions is simple. With power utility and positive consumption growth, the future marginal utility of consumption is low compared with the marginal utility of present consumption. Increasing $\phi$ intensifies this, so that a higher interest rate is required to discourage households from attempting to reallocate consumption from the future to the present. The impact of increasing $b$ or $h$ is quite different. This has the effect of increasing the future habit stock and, other things the same, this raises the marginal utility of future consumption, reducing the incentive to reallocate consumption toward the present.

In sum, accounting for the equity premium by increasing curvature is more likely to avoid counterfactual implications for the risk free rate if it is done by increasing $b$ or $h$, than if it is done by increasing $\phi$. For a further discussion of related issues, see Campbell and Cochrane (1995) and Weil $(1989,1992)$.

\section{The Equity Premium}

The curvature and capital gains channels correspond to the two arguments in the conditional covariance expression for the equity premium:

$$
r_{t}^{e p}=\frac{\mathcal{E}_{t}\left(1+r_{t+1}^{e}\right)}{1+r_{t}^{f}}=1-\operatorname{Cov}_{t}\left(\beta \frac{\Lambda_{c, t+1}}{\Lambda_{c, t}}, \frac{Z_{t+1}+P_{k, t+1}}{P_{k, t}}\right)
$$


where $\operatorname{Cov}_{t}(x, y)$ denotes the date $t$ conditional covariance between $x$ and $y$. Let $\Delta E r_{t}^{e p}$ denote the change in mean of the equity premium due to a change in preferences. Our decomposition is:

$$
\Delta E r_{t}^{e p}=\delta_{\Lambda} E r_{t}^{e p}+\delta_{P_{k}} E r_{t}^{e p}
$$

where $\delta_{\Lambda} E r_{t}^{e p}$ and $\delta_{P_{k}} E r_{t}^{e p}$ measure the curvature channel and the price of capital channel, respectively. We define $\delta_{\Lambda} E r_{t}^{e p}$ as the change in the mean equity premium due to a change in the utility function, holding fixed the distribution of $\left(Z_{t+1}+P_{k, t+1}\right) / P_{k, t}$ and $C_{t+1}$ across dates and states of nature. The capital gains channel, $\delta_{P_{k}} E r_{t}^{e p}$, is simply defined as the residual: $\delta_{P_{k}} E r_{t}^{e p}=\Delta E r_{t}^{e p}-\delta_{\Lambda} E r_{t}^{e p}$.

\subsection{Quantitative Results}

In this section we present our quantitative results for the exchange economy. First, we discuss our method for assigning values to the model parameters. Second, we document the importance of the capital gains channel. We do this by exhibiting the sensitivity of the equity premium to the persistence of consumption growth in the power utility model. Also, we use the decomposition in (3.16) to quantify the magnitude of the curvature and capital gains channels under habit persistence. Third, we document the ability of habit persistence preferences to account for key features of asset prices in our exchange economy.

\section{Parameter Values}

We adopt the normalization, $K=1$. The equilibrium consumption process (i.e., the technology shock $Z_{t}$ ) was chosen to be consistent with the observed mean, standard deviation, and autocorrelation of quarterly US per capita consumption growth. ${ }^{9}$ This requires setting

$$
\bar{\theta}=0.0045, \sigma=0.0053, \rho=0.34
$$

\footnotetext{
${ }^{9}$ Our measure of consumption is private consumption of nondurables and services, plus a measure of the service flow from the stock of durables. The data cover the period 1959.1 to 1989.4, and are discussed in Christiano [1988] and Fisher [1994]. Consumption growth at different levels of time aggregation have different autocorrelation patterns (see Heaton $(1993,1995)$ ). Accounting for this phenomenon is beyond the scope of this paper.
} 
We set $\beta=0.99999$ to maximize the model's ability to account for the observed risk free rate. We adopt this value of $\beta$ throughout the analysis.

Conditional on these parameter values, the two habit persistence parameters were set to optimize the model's implications for the mean equity premium and risk free rate. Our metric for this is $\mathcal{L}(\psi)$, where:

$$
\mathcal{L}(\psi)=\left[\hat{\nu}_{T}-f(\psi)\right] \hat{V}_{T}^{-1}\left[\hat{\nu}_{T}-f(\psi)\right]^{\prime}
$$

and $\psi=(b, h)$. Also, $\hat{\nu}_{T}$ is the $2 \times 1$ vector of point estimates for the risk free rate and the equity premium reported in Cecchetti, Lam and Mark (1993) (CLM), and the $2 \times 2$ matrix $\hat{V}_{T}$ is their estimate of the underlying sampling variance. Finally, $f$ is the model's implied risk free rate and equity premium given $\psi$. We executed this mapping by computing the average of these variables across 500 artificial data sets, each of length 120 . We considered $\psi \in \Psi$, a grid of points, $b, h$, in the unit box having the property that $C_{t} \leq X_{t}$ and $\Lambda_{c, t} \leq 0$ are never observed in the Monte Carlo simulations used to evaluate $f$. Let

$$
J=\mathcal{L}\left(\hat{\psi}_{T}\right)
$$

where $\hat{\psi}_{T}$ minimizes $\mathcal{L}(\psi)$ over $\psi \in \Psi$. In practice, we could not find values of $\psi$ which set $J=0$. We find $\hat{\psi}_{T}=(0.58,0.3)$, with $J=0.37$.

\section{Power Utility}

Results for analyzing the economy with power utility are summarized in Figure 1. That figure indicates (see 'US data') the sample averages for the risk free rate and the equity premium taken from CLM. In addition, we report 1 percent and 5 percent confidence ellipses, based on CLM's reported $\hat{V}_{T}$ matrix. Results for several versions of the exchange economy with power utility are presented.

The curve marked 'power utility, consumption growth autocorrelation $=0.34$ ' adopts the parameter values in (3.17). Moving from left to right, each letter ' 0 ' reports $f(\psi)$ for a different value of $\phi$, with $\phi=1,2,3,4,5,10,15,20,25,30,35$. There are two basic findings here. First, consistent with the nonstochastic analysis reported above, increasing curvature 
with power utility preferences produces a rise in the average risk free rate. Second, increasing curvature results in a fall in the equity premium. For $\phi$ exceeding 5 the equity premium is negative, with equity actually being a good hedge against risk.

To understand this result, we studied three other versions of our model. First, we repeated the calculations with $\rho=-0.34$ (see 'power utility, consumption growth autocorrelation $=$ $\left.-0.34^{\prime}\right)$. This change in the autocorrelation of consumption growth has essentially no effect on the monotone relationship between the risk free rate and curvature, but the effect on the equity premium is substantial. Now the equity premium rises monotonically with curvature. Second, we simulated a version of the model in which the parameters of the equilibrium consumption growth process are taken from Mehra and Prescott (1985). They based their parameter values on annual US data covering the period 1889-1978, in which the first order autocorrelation of consumption growth is -0.14 (see 'Mehra-Prescott, consumption growth autocorrelation $\left.=-0.14^{\prime}\right)$. Note that now the risk free rate initially rises, then falls, as curvature rises. In addition, consistent with the version of our model with $\rho=-0.34$, the equity premium rises monotonically with curvature. Third, we altered the Mehra-Prescott parameterization by switching the sign on $\rho$ (see 'Mehra-Prescott, consumption growth autocorrelation $=0.14^{\prime}$ ) This has a very large impact on the equity premium. It now falls sharply with increased curvature. Significantly, none of the perturbations considered places the power utility model anywhere close to the US data.

We infer from these computational experiments that the autocorrelation of consumption growth is critical for determining whether higher curvature produces a positive or negative equity premium. This finding impressively illustrates the importance of the capital gains channel in determining the equity premium, since by construction the curvature channel plays no role with variations in $\rho$.

Insight into the role of $\rho$ can be obtained by making use of a simple permanent incometype argument, and the covariance formula in (3.15). The sign of $r_{t}^{e p}$ depends upon the sign of the conditional covariance between $\Lambda_{c, t+1}$ and $Z_{t+1}+P_{k, t+1}$. When technology growth is positively autocorrelated, a date $t+1$ state of nature in which $Z_{t+1}$ is high signals an even greater rise in technology at later dates, and thus a rise in households' long run consumption opportunities. Under power utility, households have an incentive to adjust consumption 
immediately to its long-run potential, and this implies a large jump in desired $C_{t+1}$. However, to increase consumption by more than output, households must reduce their accumulation of equity and this in turn translates into a reduced demand for capital. The latter, in view of the fixed supply of capital, translates into a fall in its price, $P_{k, t+1}$. If this price effect is strong enough to overcome the jump in $Z_{t+1}$ itself - a result that is more likely, the greater is $\phi$ - then the conditional covariance in (3.15) would be positive, implying the negative equity premia that we see in Figure 1.

If instead technology growth is negatively autocorrelated, then a high $Z_{t+1}$ signals a smaller increase - perhaps even a reduction - in long run consumption prospects. Under these circumstances, adjusting consumption to its long-run potential dictates shifting $C_{t+1}$ up by less than the rise in date $t+1$ output, thus giving rise to an increased demand for capital. This drives up $P_{k, t+1}$, guaranteeing that the covariance in (3.15) is negative and that the equity premium is positive. ${ }^{10}$

We think these results make clear that to understand the sensitivity of the equity premium to $\rho$, one must understand the impact of changes in $\rho$ on the dynamics of the price of capital, i.e., the capital gains channel.

\section{Habit Persistence}

Results for analyzing the economy with habit persistence utility are summarized in Figure 2. The figure reproduces the empirical observations and confidence ellipsoids from Figure 1. The mean equity premium and risk free rate corresponding to a subset of $(b, h) \in \Psi$ are also reported. To gain insight into the relation of $b$ and $h$ with asset returns, we find it useful to arrange the results in a particular way. That is, we consider $(b, h)$ 's that imply non-stochastic steady state values of $X_{t} / C_{t}$, denoted by $x$, equal to $0.85,0.83,0.81$, and 0.30 . For the last two values of $x$, we consider $h=0,0.10,0.20, \ldots, 0.90,0.95 .^{11}$ For $x=0.85$ and $x=0.83$

\footnotetext{
${ }^{10}$ These observations can be illustrated with a simple example. Let $C_{t+1} / C_{t}=\exp \left(\theta_{t+1}\right)$, with $\theta_{t}=$ $\bar{\theta}+\varepsilon_{t}+\rho \varepsilon_{t-1}$, and $\varepsilon_{t} \sim I I N\left(0, \sigma_{\varepsilon}\right)$. Then,

$$
P_{k, t+1}=\mathcal{E}_{t+1} \sum_{j=1}^{\infty} \beta^{j} \frac{\Lambda_{c, t+1+j}}{\Lambda_{c, t+1}} C_{t+j+1} .
$$

In the power utility case, this implies $d \log \left(P_{k, t+1}\right) / d \varepsilon_{t+1}=1+(1-\phi) \rho$, which may be negative if $\rho>0$ and $\phi>1$.

${ }^{11}$ Given values of $x$ and $h$, the value of $b$ is implied by the condition, $x=b /(\exp (\bar{\theta})-h)$.
} 
only the first 9 and 8 values of $h$ are reported, respectively. Note that for each value of $x$, the equity premium-risk free rate combinations form a half-ellipse: for small values of $h$, the equity premium and risk free rate are both decreasing in $h$, for given $x$. For larger values of $h$, the equity premium continues to be decreasing in $h$, but the risk free rate now begins to increase. Note also that the half-ellipses shift down and get smaller with decreasing $x$. As $x$ gets even smaller, the half-ellipses converge to an equity premium of 0.03 percent and a risk free rate of 1.8 percent, after rounding.

The point in Figure 1 (and among all $b, h \in \Psi$ ) closest to the US data is $b=0.58, h=0.3$, with $x=0.83$. At this point, the risk free rate is 1.68 percent, and the equity premium is 6.86 percent. This is close to the US numbers, when sampling uncertainty is taken into account. Statistical results for this model economy are provided in Table 1a in the columns marked 'Exchange Economy'. The column marked 'No Habit' corresponds to the parameterization $\phi=1, b=h=0$, while 'Habit' corresponds to the model with habit persistence, evaluated at the estimated parameters. The US numbers are also reported in Table 1a. Note that, although the model does well in accounting for the mean risk free rate and equity premium, it does less well in accounting for the variance of these objects.

Table 1a also reports dynamic properties of the model's $P_{k}$, after logging and HodrickPrescott filtering. The volatility of this variable jumps to around 9.5 percent with the introduction of habit persistence, and its correlation with output (the latter being logged and HP filtered too) is about 0.5 . To evaluate the empirical plausibility of these implications, we compare them with the properties of several measures of stock prices, which are reported in Table 1b (multiply the results in Table $1 \mathrm{~b}$ by 2 to get $\sigma_{P_{k}}$ ). We find that the model's implied volatility of $P_{k}$ conforms well with its empirical counterpart. However, the model slightly overstates the correlation of stock prices with GDP, which is in the neighborhood of about 0.30 . We infer that, apart from the second moment properties of asset returns, this model does reasonably well.

Finally, to quantify the curvature channel, we considered the impact of the change, $(b=h=0)$ to $(b=0.8, h=0)$. For this, $\delta_{\Lambda} E r_{t}^{e p}=1.0003831-1.0000281$, and $\Delta E r_{t}^{e p}=$ $1.005244-1.0000281$, so that $\delta_{\Lambda} E r_{t}^{e p} / \Delta E r_{t}^{e p}=0.07$. Thus, of the full increase in the equity premium (here, expressed at a quarterly rate), 7 percent is accounted for by the curvature 
channel, and 93 percent is accounted for by the capital gains channel.

\section{One-Sector Production Economy}

In this section, we modify the production side of our economy by allowing for capital accumulation and elastic labor supply. We show that these modifications essentially eliminate the equity premium, even with habit persistence preferences.

\subsection{The Model}

At date 0 the household's preferences are:

$$
\mathcal{E}_{0} \sum_{t=0}^{\infty} \beta^{t} \frac{\left[\left(C_{t}-X_{t}\right)\left(1-h_{t}\right)^{\nu}\right]^{1-\phi}-1}{1-\phi}
$$

where $h_{t}$ denotes time $t$ labor, $X_{t}$ is the habit stock, defined in (3.2), and:

$$
0 \leq h_{t} \leq 1, \quad \forall t \geq 0
$$

The resource constraint is:

$$
K_{t}^{\alpha}\left(Z_{t} h_{t}\right)^{1-\alpha} \geq C_{t}+K_{t+1}-(1-\delta) K_{t}
$$

where $0<\delta, \alpha<1$. The variable $Z_{t}$ is a technology shock satisfying

$$
Z_{t}=\exp \left(\theta_{t}\right) Z_{t-1}, \quad \theta_{t} \sim N\left(\bar{\theta}, \sigma^{2}\right), \quad \forall t \geq 0
$$

We consider the same sequence-of-markets equilibrium concept used in the previous section, suitably modified to include the investment and labor-leisure choices. The quantities in this allocation are known to solve the planning problem: maximize (4.1) subject to (4.2)(4.4) and the non-negativity constraints, $K_{t+1}, C_{t} \geq 0$. The rate of return on the risk free 
asset, $B_{t}$, is computed using (3.12), (3.13), and the rate of return on equity is:

$$
r_{t+1}^{e}=\alpha\left(\frac{Z_{t+1} h_{t+1}}{K_{t+1}}\right)^{1-\alpha}-\delta
$$

\subsection{Result: No Equity Premium}

We used the following parameter values for the version of our model with habit persistence: $\alpha=0.36, \delta=0.021, \phi=1$, and $\nu=2$. For empirical evidence on the first two of these, see Christiano and Eichenbaum (1992). The given value for $\nu$ was chosen to assure that the model implies households work $1 / 3$ of available time. Finally, the parameters for the technology process, $\bar{\theta}$ and $\sigma$, were set equal to 0.40 percent and 1.8 percent, respectively. These correspond to empirical point estimates for the mean and standard deviation of the Solow residual (see, for example, Christiano and Eichenbaum [1992]). Figure 3 reports the risk free rate, equity premium combinations associated with a grid of $b$ and $h$ designed to cover the feasible set of these parameters. Note that no value of $b$ and $h$ comes even close to accounting for the US data. Thus, the production economy stands in striking contrast to the exchange economy, in that the equity premium and risk free rates are essentially invariant to whether there is habit persistence or log utility.

The financial statistics pertaining to the $b=h=0$ and $b=0.80, h=0$ cases are reported in Table 1a in columns labelled 'No Habit' and 'Habit', respectively. The business cycle properties of quantity variables are reported in Table 3 . Note from Table 1a that the equity premium drops from 6.86 percent in the exchange economy to essentially zero in the production economy.

\subsection{Diagnosing the Result}

To understand the reason there is no equity premium in this economy, we begin by analyzing the general equilibrium effects on consumption and other quantity variables of converting from $b=h=0$ to $b=0.8, h=0$. These effects are substantial because a household with habit persistence preferences has a strong incentive to smooth the response of consumption to a shock. Moreover, the technology described in (4.3) offers at least three mechanisms through which this can be accomplished: variations in labor effort, variations in the rate of 
capital accumulation, and variations in the sectoral allocation of factors of production.

The impulse response functions displayed in Figure 4 document how agents in the $b>0$ economy exploit these opportunities relative to agents in the $b=0$ economy. The figures display the $\log$ deviation of a variable from a steady state growth path in response to a single, one standard deviation innovation in $\theta_{t}$. The results have been multiplied by 100 to convert them into percent terms. In measuring quantities in the model, we follow the National Income and Product Accounts practice. Namely, we measure quantities in base year prices, which we set to unity.

Figure 4 a shows that the impact on consumption of a shock is greatly reduced in the $b>0$ economy (see the solid line) compared with the $b=0$ economy (dashed line). Eventually the two responses converge, but this takes about 12 model periods (three years). At the aggregate level, this smoothing of consumption is accomplished in part by a relatively strong investment response (Figure $4 \mathrm{~b}$ ) and a relatively weak employment response (Figure 4c).

For further diagnosis of the factors underlying the smoothed consumption response, we find it useful to adopt the two-sector interpretation of our one-sector model. Figures $4 \mathrm{~d}$ and 4e show that with $b>0$ there is a strong shift of labor (and - not shown - capital) resources out of the consumption goods sector and into the investment goods sector. It is well known that, with $b=0$, there is some shift in resources out of the consumption sector and into the investment goods sector after a positive technology shock. The prediction of the standard real business cycle model that employment in the consumption sector is countercyclical is counterfactual, and the adoption of habit persistent preferences evidently exacerbates that problem.

The amplified positive aggregate investment response with $b>0$ masks much larger effects at the sectoral level. There is a substantial increase in the already positive response of investment in capital for the investment goods industry. The production of capital goods for the consumption goods industry experiences a greater decline with $b>0$ than with $b=0$. This reflects efforts to shift resources out of the consumption sector dynamically, and is one way that households bring about the slow rise in consumption evident in Figure 4a.

These findings are reflected in the second moment statistics reported in Table 3 . For example, those statistics show a substantial reduction in the standard deviation of consump- 
tion with $b>0$. At the same time, there is a sharp increase in the variability of investment. Although there is an absolute fall in the volatility of employment, the reduction is less than the reduction in output.

The preceding observations are consistent with the hypothesis that the absence of an equity premium in the one-sector production economy reflects the smoothing of consumption across states of nature. According to this hypothesis, the general equilibrium smoothing of consumption prevents a rise in the equity premium that would have occurred otherwise.

Taken literally, this hypothesis is incorrect. In particular, suppose there had been no general equilibrium impact on consumption or the rate of return on capital, in response to the change in preferences, $(b=h=0)$ to $(b=0.8, h=0)$. Then, according to the covariance formula, (3.15), the equity premium would have gone from 1.0000028 to 1.000057 , which is only a trivial increase. That is, had no consumption smoothing or change in the rate of return on capital occured, the equity premium would have jumped to a mere $100\left(1.000057^{4}-1\right)=0.02$, or, two-one-hundreds of a percent per year. ${ }^{12}$ The failure of habit persistence to generate an equity premium in the one-sector production economy is not a consequence of the fact that households choose a smooth consumption sequence.

There is nevertheless a sense in which the absence of an equity premium and the smoothing of consumption are related. In a one-sector economy the marginal rate of transformation between investment and consumption goods is unity, that is to say, the supply of capital goods is infinitely elastic. While this is the reason it is feasible for households to smooth consumption, it also has the implication that the equilibrium price of capital is constant. The latter fact essentially eliminates the fluctuations across states of nature in the rate of return on equity, and is the reason why there is no equity premium. Again, this illustrates the central role played by the capital gains channel. In the next section we put this intuition to work.

\footnotetext{
${ }^{12}$ The 0.02 result is not strictly comparable to what is in Table 1a, because of Jensen's inequality. The 0.02 is the annualized average equity premium, while what is in the table is the average of annualized equity premia. The latter can be expected to be larger.
} 


\section{Two-Sector Economies}

Here we consider three modifications of the model economy analyzed in the previous section. In our first modification, we assume that consumption and investment goods are produced in distinct sectors, and that the sectoral allocation of the date $t$ capital stock is a function of the previous period's state of nature. In our second modification, we assume households also decide their date $t$ allocation of sectoral employment prior to the realization of the date $t$ state of nature. We then further modify the model to allow firms to issue risk-free debt, in addition to equity, to finance their purchases of capital. The model embodying all three modifications implies a risk free rate and return on equity which lie within a 5 percent confidence bound about the corresponding empirical estimates. We also examine the business cycle implications of this model.

\subsection{A two-sector economy with full labor mobility}

The quantity allocations in a sequence-of-markets competitive equilibrium solve the programming problem:

$$
\max \mathcal{E}_{0}\left\{\sum_{t=\mathbf{0}}^{\infty} \beta^{t} \frac{\left[\left(C_{t}-X_{t}\right)\left(1-h_{i, t}-h_{c, t}\right)^{\nu}\right]^{1-\phi}-1}{1-\phi}\right\}
$$

subject to:

$$
\begin{gathered}
K_{c, t}^{\alpha}\left(Z_{t} h_{c, t}\right)^{1-\alpha} \geq C_{t}, \\
h_{c, t}, h_{i, t}, h_{c, t}+h_{i, t} \in[0,1], \quad \forall t \geq 0,
\end{gathered}
$$

and

$$
K_{i, t}^{\alpha}\left(Z_{t} h_{i, t}\right)^{1-\alpha}+(1-\delta)\left(K_{\mathrm{c}, t}+K_{i, t}\right) \geq K_{c, t+1}+K_{i, t+1}
$$

Here, the subscripts $c$ and $i$ denote the consumption and the investment sectors, respectively. As before, we require that the sum, $K_{\mathrm{c}, t+1}+K_{i, t+1}$, be chosen as a function of the date $t$ state of nature. Unlike before, we now also require that the individual terms, $K_{\mathrm{c}, t+1}$ and $K_{i, t+1}$, be chosen as a function of the date $t$ state of nature. Finally, we assume that the state of technology, $Z_{t}$, is drawn from the time series representation described in (4.4). Let 
$\Lambda_{c, t}$ and $\Lambda_{i, t}$ denote the Lagrange multipliers on (5.2) and (5.4).

We assume the same financing arrangements that we have used up to now: firms have a one period planning horizon and to operate in period $t+1$, they must issue enough equity in period $t$ to finance their purchase of whatever quantity of capital they plan to use. Different equity is used to finance consumption and investment goods firms. It is readily verified that the rate of return on equity in market $x$ is $r_{x, t}^{e}, x=i, c$, where

$$
r_{c, t+1}^{e}=\frac{\alpha\left[\frac{Z_{t+1} h_{c, t+1}}{K_{c, t+1}}\right]^{1-\alpha}+P_{k, t+1}(1-\delta)}{P_{k, t}}-1
$$

for $x=c$ and

$$
r_{i, t+1}^{e}=\frac{P_{k, t+1} \alpha\left[\frac{Z_{t+1} h_{i, t+1}}{K_{i, t+1}}\right]^{1-\alpha}+P_{k, t+1}(1-\delta)}{P_{k, t}}-1
$$

for $x=i$. The rate of return on the market portfolio, $r_{t}^{e}$, is:

$$
r_{t+1}^{e}=\frac{K_{c, t+1}}{K_{t+1}} r_{c, t+1}^{e}+\frac{K_{i, t+1}}{K_{t+1}} r_{i, t+1}^{e}
$$

where $K_{t+1}=K_{c, t+1}+K_{i, t+1}$.

To find the objects in competitive equilibrium, first get the quantities and multipliers by solving the planning problem stated above. Second, find $P_{k, t}$ using the relation, ${ }^{13}$

$$
P_{k, t}=\Lambda_{i, t} / \Lambda_{c, t}
$$

The price, $P_{k, t}$, varies with the realization of the date $t$ state of nature because of diminishing productivity of labor as labor is reallocated between sectors, and the distribution of capital is fixed. The rate of return, $r_{t}^{f}$, on the risk free asset is obtained as before, using (3.12)-(3.13). Then, the various equity rates of return are obtained from (5.5)-(5.7).

The model is parameterized exactly as the one-sector model in the previous section. We adopt these parameter values because they meet the criteria we set out when we estimated

\footnotetext{
${ }^{13}$ There is a slight inconsistency here, relative to the endowment economy. There, $P_{k, t}$ was a variable that grows in equilibrium, while here it is not. The difference is that there the stock of capital was constant and the payoff per unit of capital was growing while here the stock of capital is growing and the payoff per unit of capital is stationary.
} 
them for the one sector production economy. In particular, they allow the model's implication for mean hours worked and the mean growth rate and variance of the Solow residual to coincide with their sample analogs.

Values for the risk free rate and equity premium implied by feasible $(b, h)$ combinations are displayed in Figure 5. Note that the model - though a little closer to the data now - is still not close even to the 1 percent confidence interval for the data. The parameterization that is closest to the data - according to the metric defined in section 3 - is one with $b=0.9, h=0$. The financial properties of this model are reported in Table 1a. The business cycle properties are reported in Table 3.

Figure 7 reports the impulse response functions for the $b=h=0$ ('Full No Habit' long dashes) and $b=0.9, h=0$ ('Full Habit' short dashes) versions of the model. The quantity effects of habit persistence resemble very closely the ones seen in Figure 4 for the one-sector economy. For example, consumption is considerably smoother, and investment more volatile with the introduction of habit persistence. The success that households have in smoothing consumption reflects the fact that, although capital supply is not infinitely elastic, it still exhibits considerable short-term elasticity in this model. This high elasticity also underlies the fact that the volatility of $P_{k}$, though positive, is still very small. This in turn accounts, via the capital gains channel, for the fact that there is not a substantial equity premium in this model.

These considerations suggest that a version of the model with a smaller short term elasticity of capital supply is required. One avenue for obtaining this is suggested by the results in Table 3, which indicate that gross investment in capital for the investment sector is negative 9.4 percent of the time. A non-negativity constraint on gross investment would therefore be binding in this model. Imposing this constraint would have the effect of making capital supply more inelastic, at least in the range of low investment. As expected, when we experimented with modifications like this, the equity premium rose, but only by a modest amount. 


\subsection{A two-sector economy with limited labor mobility}

In this section, we investigate the impact of requiring that the household's date $t$ labor supply decisions be made prior to the realization of the current state of nature. After the state of technology is realized, the sectoral labor markets meet and clear (subject to the predetermined labor supply) at a competitive wage. In effect, this makes the short-term supply of capital completely inelastic, as in the exchange economy.

The formulas for the risky and risk-free rates of return are not altered by this modification, and so are not repeated here. For the same reasons cited in the previous subsection, the model parameter values for the one-sector model are adopted here. Values of the risk free rate and equity premium associated with feasible $(b, h)$ combinations are reported in Figure 6. Note that now the model is noticeably closer to the data, although it is still not within the 1 percent confidence ellipse. Note too, that the volatility of the price of capital has now increased by a factor of 10 , moving this model implication closer to the empirical results reported in Table 1b. This result is not surprising, in view of the short-term inelasticity of capital supply. Interestingly, the model correlation between the price of capital and output is now 0.25 , which is very close to the data.

To gain further insight into the reasons for these results consider again Figure 7. In calculations not documented here, we found that impulse response functions for the no habit, full and limited labor mobility models are roughly identical. Figure 7 then indicates that, in the limited labor mobility model, the impulse response functions of quantities are essentially invariant to the introduction of habit persistence preferences. This reflects the fact that the inelasticity of capital supply in effect prevents households from smoothing consumption. The consequent sharp response in the price of capital is indicated in Figure 7d.

\subsection{The Effect of Financial Leverage}

Consider now the model economy in the previous subsection, with the modification that we also allow firms to issue risk free debt. This debt is identical, in maturity and rate of return, to the privately issued bonds considered until now. Unlike the risk-free security of the previous sections, the firm-issued bond will be traded in equilibrium. 
As is well known, profit maximizing firms are indifferent to the debt-equity composition of their liabilities in an environment such as ours. Moreover, the quantity allocations in general equilibrium are invariant to the pattern, across dates and states of nature, of the debt to equity ratio in firm liabilities (the Modigliani-Miller theorem). What is not invariant to the debt to equity ratio, is the mean and variance of the return on equity. The premium of the return on equity over debt is strictly increasing in the debt to equity ratio. This simply reflects that equity must bear the full degree of uncertainty in firm cash flow across states of nature. In the experiments analyzed below, we consider the equity premium for an economy with a debt to equity ratio similar in magnitude to that reported for the US economy.

With leverage, the finance constraint for a firm in industry $x$ is:

$$
P_{k, t} K_{x, t+1} \leq S_{x, t}+B_{x, t}
$$

for $x=i, c$. In period $t+1$, the firm in sector $x$ hires labor and carries on production. Let $\pi_{x, t+1}$ denote its revenues from sales - output, $Y_{x, t+1}$, plus the undepreciated stock of capital net of expenses on labor and on its financial obligations. All terms in $\pi_{x, t+1}$ are denominated in consumption units. We require that the firm's expenses not exceed its receipts:

$$
\begin{aligned}
\pi_{x, t+1}= & Y_{x, t+1}+(1-\delta) K_{x, t+1} P_{k, t+1} \\
& -W_{x, t+1} h_{x, t+1}-\left(1+r_{x, t+1}^{e}\right) S_{x, t}-\left(1+r_{t}^{f}\right) B_{x, t} \geq 0
\end{aligned}
$$

where $r_{x, t+1}^{e}$ and $r_{t}^{f}$ denote the rates of return on equity and debt, respectively. Also, $W_{x, t+1}$ denotes the wage paid to workers in sector $x$, expressed in period $t+1$ consumption units. The firm takes prices and rates of return, $P_{k, t}, r_{x, t+1}^{e}, r_{t}^{f}, P_{k, t+1}, W_{x, t+1}$, as given. At date $t$, the objective of the firm is:

$$
\max _{S_{x, t}, K_{x, \ell+1}, B_{x, t}} \mathcal{E}_{t} p_{c, t+1} \max _{h_{x, t+1}} \pi_{x, t+1}
$$

subject to (3.12), (5.9) and (5.10). The firm is assumed to take $p_{c, t+1}$ as given. Assuming 
an interior solution to (5.11), the first order condition for $h_{x, t+1}$ is:

$$
m p l_{x, t+1}=W_{x, t+1}
$$

where $m p l_{x, t+1}$ is the marginal product of labor in industry $x$, expressed in consumption units. The first order condition associated with $S_{x, t}$ is:

$$
\mathcal{E}_{t} p_{c, t+1}\left[\frac{m p k_{x, t+1}+(1-\delta) P_{k, t+1}}{P_{k, t}}-\left(1+r_{t+1}^{e}\right)\right]=0
$$

where $m p k_{x, t+1}$ is the marginal productivity of capital in sector $x$, measured in consumption units. The first order condition for $B_{x, t}$ is (5.13) rith $r_{t+1}^{e}$ replaced by $r_{t}^{f}$.

Linear homogeneity guarantees that the only equilibrium is one in which profits, (5.11), are zero. Given the weak inequality in (5.10), this implies $\pi_{x, t+1}=0$ for all $t$ and states of nature. This, in conjunction with the facts: (i) profit maximization causes (5.9) to be satisfied as an equality, (ii) linear homogeneity implies $Y_{x, t+1}=m p k_{x, t+1} K_{x, t+1}+m p l_{x, t+1} h_{x, t+1}$ and (iii) the first order condition for labor, (5.12), allows us to derive the following expression for the rate of return on equity in sector $x$ :

$$
1+r_{x, t+1}^{e *}=\frac{m p k_{x, t+1}+(1-\delta) P_{k, t+1}}{P_{k, t}}\left(1+\gamma_{x, t}\right)-\left(1+r_{t}^{f}\right) \gamma_{x, t}
$$

where $\gamma_{x, t}=B_{x, t} / S_{x, t}$ is the debt to equity ratio and $r_{x, t+1}^{e *}$ is the leveraged rate of return on equity. We impose $\gamma_{x, t}$ exogenously, given that it is not determined in equilibrium.

Rearranging (5.14) and taking into account the formula for the unleveraged rate of return on equity, $r_{x, t}^{e}$, in (5.5) and (5.6), we get the following expression for the equity premium:

$$
r_{x, t+1}^{e *}-r_{t}^{f}=\left(r_{x, t+1}^{e}-r_{t}^{f}\right)\left(1+\gamma_{x, t}\right)
$$

From this, it is evident that leverage raises the equity premium proportionally. Obviously, if the equity premium were small in the unleveraged economy, then leveraging would have only a small impact on the equity premium. For example, (5.15) indicates that to convert an unleveraged equity premium of 1 percent into a leveraged equity premium of 5 percent 
requires a debt to equity ratio of 4 . The actual debt to equity ratio is closer to $2 / 3 .{ }^{14}$

In our computations, we study equilibria in which $\gamma_{i, t}=\gamma_{c, t}=\gamma=2 / 3$. In other respects, the model parameterization conforms to what was used in previous subsections. Table 2 shows that the introduction of leverage in this way raises the equity premium by roughly a factor of two in practically every model we have considered. ${ }^{15}$ Figure 8 shows that we are now well within the 5 percent confidence interval for the equity premium and risk free rate.

\subsection{Business Cycle Implications}

The business cycle implications of the model just analyzed, what we refer to as 'our model', are identical to those of the model with no leverage. In Table 3 we see that its predictions conform closely with those of the standard real business cycle model, namely the one sector economy, with no habit. The performance of our model is poor with respect to the volatility of aggregate hours worked, and with respect to the cyclical behavior of hours worked in the consumption sector. But, on these dimensions it does no worse than the standard model.

There are two other dimensions on which our model actually does better than the standard model. First, the standard model implies that the first order autocorrelation of equilibrium output growth essentially coincides with the assumed autocorrelation of the growth rate of technology, which is zero here. ${ }^{16}$ The coincidence of these two autocorrelations reflects the well-known absence of internal propagation in that model (see Christiano (1988) and Cogley and Nason (1995).) This absence of internal propagation is a problem in view of the fact that a standard measure of technology growth indicates little first order autocorrelation, while the estimated first order autocorrelation of output growth is 0.37 , with a two standard deviation confidence interval of $[0.23,0.51]$ (see Table 4.) In our model, by contrast, the autocorrelation of equilibrium output growth is 0.20 , which is very close to this confidence interval. The model exhibits persistence in output growth, despite the fact that the state of

\footnotetext{
${ }^{14}$ See Benninga and Protopapadakis [1990] and literature cited there.

${ }^{15}$ The impact of leveraging is not precisely what is predicted by (5.15), since in the table we compute the equity premium with the underlying rates compounded at an annual rate, while the objects in (5.15) are denominated at a quarterly rate.

${ }^{16}$ We computed the first order autocorrelation of output growth in 500 artificial data sets of 120 observations each, generated using the standard model. The average across the 500 autocorrelations was 0.0009 , and the associated Monte Carlo standard error was 0.004 .
} 
technology is a random walk.

Our model also dominates the standard model in relation to the excess sensitivity puzzle. To define this puzzle, consider the following relation:

$$
\Delta C_{t}=\mu+\lambda \Delta Y_{t}+\theta r_{t}+\varepsilon_{t}
$$

Here, $\Delta x_{t} \equiv \log \left(x_{t}\right)-\log \left(x_{t-1}\right)$. Campbell and Mankiw $(1989,1991)$ estimate the parameters in this relation by a two-step instrumental variables procedure: in the first step they replace the left and right variables by their regression forecasts based on a set of instruments, and in the second step they run an ordinary least squares regression to estimate $\mu, \lambda$, and $\theta$. A potential pitfall, particularly for estimating $\lambda$, is the possibility that the instruments are not correlated with $\Delta Y_{t}{ }^{17}$ To help guard against this in practice, it is useful to obtain a measure of $R_{\Delta y}^{2}$, the $R$-bar squared in the regression of $\Delta Y_{t}$ on the instruments. In Christiano (1989), Monte Carlo evidence is presented which suggests that the $R_{\Delta y}^{2}$ reported in Campbell and Mankiw (1989), 0.047, is sufficiently large that the resulting estimate of $\lambda$ is not simply an artifact of poor instrument quality. In our model, there is enough persistence in equilibrium output growth that the implied $R_{\Delta y}^{2}$ is in the acceptable range (see Table 4).

Campbell and Mankiw (1989) interpret their empirical estimates of (5.16), reported in Table 4 , as reflecting that the forecastable component of consumption growth is an increasing function of the forecastable components of output growth and the interest rate and, moreover, that the latter plays a smaller role than the former. It is interesting to note from Table 4 that our model's implication for $\lambda$ overshoots Campbell and Mankiw's (1989) empirical estimate, though it is within the range $\lambda$ 's found using data for several European countries (see Campbell and Mankiw (1991).) Also, the value predicted by our model for the instrumental variable estimate of $\theta$ is even smaller than Campbell and Mankiw's (1989) estimates. Thus, our model can account for the evidence that the forecastable part of consumption growth is an increasing function of the forecastable part of output growth, and that it is more closely related to this than it is to the forecastable part of the interest rate. ${ }^{18}$ That

\footnotetext{
${ }^{17}$ For a formal analysis of these issues, see Nelson and Startz $(1990 \mathrm{a}, \mathrm{b})$.

${ }^{18}$ Baxter and Jermann (1994) document that a model with home production can also account for the excess sensitivity puzzle.
} 
a version of the standard model is incompatible with these observations is documented in Christiano (1989).

\section{Concluding Remarks}

Macroeconomists have long been interested in understanding precisely where and when the complete markets, representative agent paradigm breaks down, if at all. The view is widely held that a prime example of where it falls apart is on the equity premium. An important lesson from this analysis, is that this is not so obvious. A production economy with complete markets and reasonable risk aversion was constructed that accounts moderately well both for the business cycle and for key features of asset returns. Other asset pricing lessons we take away from this analysis are that (a) habit persistence preferences and (b) multisector technologies with limitations on the intersectoral mobility of factors of production, are likely to be important elements in a successful model of the business cycle.

To understand how these elements contribute to an equity premium, recall that the key to generating an equity premium in the general equilibrium models considered here is to produce the 'right' dynamic behavior in the price of capital. In particular, innovations in the price of capital must be large, and negatively correlated with the marginal utility of consumption. Under these circumstances, equity is a bad hedge against risk, and thus requires a large premium to induce households to hold it. As we pointed out in section 2, to get the appropriate movements in the price of capital, we require that (i) households have a strong incentive to buy assets when the marginal utility of consumption is low, and to sell when the marginal utility of consumption is high, and (ii) a technology which frustrates these desires. Ingredient (a) above contributes to (i), and ingredient (b) contributes to (ii). ${ }^{19}$

We now briefly discuss some of the limitations of the analysis. First, consistent with the intuition in the previous paragraph we find, in results not reported in the paper, that our

\footnotetext{
${ }^{19}$ Recently, Rouwenhorst (1995) has explored the asset pricing implications of a general equilibrium business cycle model which resembles ours in the sense that aggregate factor supplies are determined prior to the realization of the shocks. His model nevertheless fails to generate a sizeable equity premium because it does not have ingredients (a) and (b). He adopts a one sector formulation, and a power utility function with low curvature. The one sector formulation is equivalent to a two sector model with identical production functions and with complete mobility of factors of production between sectors.
} 
model implies consumption growth and the rate of return on equity are highly correlated - more so than in the data. ${ }^{20}$ This is a long-standing puzzle for the type of equilibrium model used here. One possible resolution, which deserves formal investigation, is that the discrepancy reflects measurement error in consumption data, or in the price data used to convert nominal returns into real returns. ${ }^{21}$ Alternatively, the resolution to the puzzle may lie in a discrepancy between the marginal utility of consumption and consumption itself. There is such a discrepancy in the model of this paper, however, it is not sufficiently large quantitatively to resolve the puzzle. A second shortcoming of the model lies in its prediction for the cyclical behavior of the price of new investment goods. Our model has the implication that this coincides with the value of capital to the firm, which we associate with the price of stock. This is inconsistent with observations like those documented in Greenwood, Hercowitz and Krusell (1992) that the prices of many types of new investment goods are countercyclical, and, more generally, with the observation that Tobin's $q$ is not constant. We are currently investigating ways to confront these limitations of our model.

\footnotetext{
${ }^{20}$ Our model's predicted correlation between consumption growth and the return on equity is over 0.90 , while the corresponding object in the data is closer to a range of 0.0 to 0.3 , depending which measure of the return on equity one uses (see Christiano (1989).) That the model is also consistent with the small instrumental variables regression relationship between consumption and interest rates reflects the distinction between a regression coefficient and a correlation.

${ }^{21}$ For a discussion of measurement error in consumption data, see Wilcox (1988). Gibbons (1989) cites the measurement error in consumption data as a reason not to use these data at all in evaluating theories of asset pricing. A quantitative analysis of the impact of measurement error in prices appears in Christiano (1989). For a formal, maximum likelihood approach to estimation and testing when there is measurement error in the data, see Sargent (1989).
} 


\section{A. Some Habit Persistence Algebra}

In this appendix, we derive the coefficient of relative risk aversion $(R R A)$ and the elasticity of intertemporal substitution for habit persistence preferences. The presentation adapts the discussion in Constantinides (1990) to a discrete-time context. A similar discussion appears in Ferson and Constantinides (1991), but we need to generalize their results slightly in order to accommodate the case $h \neq 0$.

\section{A.1. Policy and Value Functions}

Here, we derive the policy function and value function for a household with habit persistence preferences and, potentially, $\phi \neq 1$. We do so under the assumption that the household faces no uncertainty and a fixed rate of interest, $1+r_{t}^{f}=1+r_{t}^{e}=\frac{\gamma^{\phi}}{\beta}$.

Let $\Lambda_{c, t}$ denote the derivative of (3.1) with respect to $C_{t}$ :

$$
\Lambda_{c, t}=\left(C_{t}-X_{t}\right)^{-\phi}-\frac{b}{h} \sum_{j=1}^{\infty}(\beta h)^{j}\left(C_{t+j}-X_{t+j}\right)^{-\phi} .
$$

The Euler equation for the household's problem is $\Lambda_{c, t}=\beta\left(1+r^{e}\right) \Lambda_{c, t+1}$, for $t=0,1, \ldots$. This is satisfied by the following class of policies, indexed by the undetermined constant, $Q$ :

$$
\left(C_{t}-X_{t}\right)=Q \gamma^{t}
$$

Taking into account (3.2), and after some algebraic manipulation, one gets

$$
C_{t}=\gamma^{t}\left[\psi^{t} X_{0}+B_{t} Q\right], \text { for } t=0,1, \ldots,
$$

where $\psi=(h+b) / \gamma$, and $B_{t}=\left(1-\frac{h}{\gamma}\right)\left[\frac{1-\psi^{t}}{1-\psi}\right]+\psi^{t}$. We assume

$$
0<h+b<\gamma,
$$

a condition satisfied in all the cases considered in the text. The parameter $Q$ is found by requiring that the intertemporal budget equation be satisfied: $\sum_{t=0}^{\infty}\left(\frac{1}{1+r^{e}}\right)^{t} C_{t}=\left(1+r^{e}\right) W_{0}$, where $W_{0}=B_{0}+S_{0}$ is the initial stock of wealth. This yields

$$
Q\left(W_{0}, X_{0}\right)=\frac{\left(\frac{\gamma^{\phi}}{\beta}-\gamma\right)\left\{\left[\frac{\gamma^{\phi}}{\beta}-(h+b)\right] W_{0}-X_{0}\right\}}{\left(\frac{\gamma^{\phi}}{\beta}-h\right)},
$$

where $X_{0}$ is the initial habit stock. Then, the value function is:

$$
v\left(W_{0}, X_{0}\right)=\frac{Q^{(1-\phi)} /(1-\phi)}{1-\beta} .
$$

Equation (A.2) for $t=0$, with $Q$ defined in (A.3), is the policy function for consumption. 
Note that

$$
\frac{d C_{0}}{d W_{0}}=\gamma\left(\frac{1}{\beta \gamma^{(1-\phi)}}-1\right)\left(\frac{\frac{\gamma^{\phi}}{\beta}-(h+b)}{\frac{\gamma^{\phi}}{\beta}-h}\right) .
$$

There are two interesting features of this expression. First, when $b=0$ and $\gamma=1$, so that $\beta\left(1+r^{e}\right)=1$, then $d C_{0} / d W_{0}=r^{e}$, exactly the prediction of standard permanent income theory. Second, $d C_{0} / d W_{0}$ is decreasing in $b$, and also decreasing in $h$, when $b>0$. This is as expected. With habit persistence, the optimal response to a decrease in wealth is to use financial markets to bring down consumption slowly so that the stock of habit has a chance to fall.

\section{A.2. Risk Aversion}

The discrete-time analog of the steady-state formula for $R R A$ provided in Constantinides (1990) is:

$$
R R A \equiv-\frac{W v_{W W}}{v_{W}}=\frac{\phi}{1-\frac{x\left(\frac{\phi^{\phi}}{\beta}-\gamma\right)}{\frac{\gamma^{\phi}}{\beta}-(h+b)}}, x=\frac{b / \gamma}{1-h / \gamma}, \gamma=-\exp (\bar{\theta}) .
$$

Here $x$ is $X_{t} / C_{t}$ along a steady-state, balanced growth path, and $\bar{\theta}$ is the growth rate of consumption. The expressions $v_{W}$ and $v_{W W}$ are the first and second derivatives of the value function, (A.4), with respect to $W$.

We briefly repeat here the standard, textbook interpretation of $R R A$. Consider the following fair bet on wealth: the household receives $W_{0}(1+\mu)$ or $W_{0}(1-\mu)$, each with probability $1 / 2$. Let $\nu$ denote the largest fraction of the household's wealth that it would be willing to sacrifice to avoid this bet:

$$
v\left(W_{0}(1-\nu), X_{0}\right)=\frac{1}{2}\left[v\left(W_{0}(1+\mu), X_{0}\right)+v\left(W_{0}(1-\mu), X_{0}\right)\right]
$$

Take a first order Taylor series expansion of the expression on the left of the equality about $W_{0}$, and a second order Taylor series expansion of the expression on the right, and solve for $\nu$ :

$$
\nu=-\frac{W_{0} v_{W W}}{v_{W}} \frac{1}{2} \mu^{2}=R R A \frac{1}{2} \mu^{2} .
$$

Now, if $\mu=0.1414$, then $\frac{1}{2} \mu^{2}=.01$. Thus, a habit persistence household faced with a 50 50 chance of loosing or increasing its wealth by 14 percent would be willing to pay $R R A$ $(=\nu \times 100)$ percent of its wealth to avoid the gamble.

\section{A.3. Intertemporal Substitution}

We exploit the fact

$$
\frac{d \log \left(C_{t+1} / C_{t}\right)}{d \log \left(1+r_{t+1}^{e}\right)}=-\frac{\Lambda_{c, t}}{C_{t} \Lambda_{c c, t}}
$$

where the object on the left of the equality is the definition of the intertemporal elasticity of substitution. We derive the object on the right of the equality, the inverse of our measure of curvature, along a balanced growth path. 
Note from (A.1) that, along a nonstochastic steady-state growth path where $C_{t}=\gamma C_{t-1}$,

$$
\Lambda_{c, t}=C_{t}^{-\phi} Q_{c}, \Lambda_{c c, t}=-\phi C_{t}^{-(\phi+1)} Q_{c c}
$$

Here

$$
Q_{c}=s^{-\phi}\left[1-\frac{b \beta / \gamma^{\phi}}{1-\beta h / \gamma^{\phi}}\right]
$$

and

$$
Q_{c c}=s^{-(1+\phi)}\left[1+\frac{b^{2} \beta / \gamma^{\phi+1}}{1-h^{2} \beta / \gamma^{\phi+1}}\right]
$$

Also, $s=1-x$ denotes the steady-state value of $\left(C_{t}-X_{t}\right) / C_{t}$. Note that $Q_{c c}$ is increasing, and $Q_{c}$ and $s$ are decreasing, in $b$ and $h$. Consequently, intertemporal substitution in steady state,

$$
-\frac{\Lambda_{c, t}}{C_{t} \Lambda_{c c, t}}=\frac{Q_{c}}{\phi Q_{c c}}
$$

is decreasing in $b$ and $h$. 


\section{References}

[1] Abel, Andrew, 1990, "Asset prices under habit formation and catching up with the Jones," American Economic Review Papers and Proceedings, vol. 80, pp. 38-42.

[2] Aiyagari, S. Rao and Mark Gertler, 1991, "Asset returns with transactions costs and uninsured individual risks," Journal of Monetary Economics, vol. 27, pp. 311-332.

[3] Barsky, Robert, T. Juster, Miles Kimball, and Matthew Shapiro, 1995, "Preference parameters and behavioral heterogeneity: an experimental approach in the health and retirement survey," unpublished manuscript, University of Michigan.

[4] Baxter, Marianne, and Urban J. Jermann, 1994, "Household production and the excess sensitivity of consumption to current income," manuscript, University of Virginia.

[5] Benninga, Simon and Aris Protopapadakis, 1990, "Leverage, time preference and the equity premium puzzle," Journal of Monetary Economics, vol. 25, pp. 49-58.

[6] Burnside, Craig, 1994, "Hansen-Jagannathan bounds as classical tests of asset pricing models," Journal of Business and Economic Statistics, vol. 12, pages 57-74.

[7] Campbell, John, and John Cochrane, 1995, "By force of habit: a consumption-based explanation of aggregate stock market behavior," National Bureau of Economic Research Working Paper 4995.

[8] Campbell, John, and N. Gregory Mankiw, 1989, "Consumption, income, and interest rates: reinterpreting the time series evidence", in Blanchard and Fischer, editors, NBER Macroeconomics Annual 1989.

[9] Campbell, John, and N. Gregory Mankiw, 1991, "The response of consumption to income: a cross-country investigation," European Economic Review, vol. 35, pp. 723767.

[10] Cecchetti, Stephen G., Pok-sang Lam, and Nelson C. Mark, 1993, "The equity premium and the risk-free rate: matching the moments," Journal of Monetary Economics, vol. 31 , pp. $21-46$.

[11] Christiano, Lawrence J. , 1988, "Why does inventory investment fluctuate so much?" Journal of Monetary Economics, vol. 21, pp. 247-280.

[12] Christiano, Lawrence J., 1989, "Comment on Campbell and Mankiw," in Blanchard and Fischer, editors, NBER Macroeconomics Annual 1989.

[13] Christiano, Lawrence J. and Martin Eichenbaum, 1992, "Current real-business-cycle theories and aggregate labor market fluctuations," American Economic Review, vol. 82, pp. $430-450$. 
[14] Christiano, Lawrence J., and Jonas Fisher, 1994, "Algorithms for solving dynamic models with occasionally binding constraints," Federal Reserve Bank of Minneapolis Staff Report 171.

[15] Cochrane, John and Lars Peter Hansen, 1992, "Asset pricing explorations for macroeconomics." NBER Macroeconomics Annual, pp. 115-165.

[16] Cogley, Tim, and Jim Nason, 1995, "Output dynamics in real-business cycle models," American Economic Review, pp. 492-511.

[17] Constantinides, George, 1990, "Habit formation: a resolution of the equity premium puzzle," Journal of Political Economy, vol. 98, pp. 519-542.

[18] Danthine, Jean-Pierre, John B. Donaldson, and Rajnish Mehra, 1992, "The equity premium and the allocation of income risk," Journal of Economic Dynamics and Control, vol. 16, pp. 509-532.

[19] Danthine, Jean-Pierre, and John B. Donaldson, 1994, "Asset pricing implications of real market frictions," manuscript, Columbia University, Graduate School of Business.

[20] Ferson, Wayne, and George M. Constantinides, 1991, "Habit persistence and durability in aggregate consumption: empirical tests." Journal of Financial Economics, vol. 29, pp. 199-240.

[21] Fisher, Jonas, 1994, "A dynamic, general equilibrium empirical analysis of real and monetary aspects of the business cycle," unpublished Northwestern University Ph.D. dissertation.

[22] Gibbons, Michael R., 1989, "On the volatility of bond prices," Carnegie-Rochester Conference in Public Policy, vol. 31, Autumn.

[23] Goolsbee, Austan, 1994, "Investment tax incentives and the price of capital goods," manuscript, MIT.

[24] Greenwood, Jeremy, Zvi Hercowitz, and Per Krusell, 1992, "Macroeconomic implications of investment-specific technological change," Institute for Empirical Macroeconomics discussion paper 76, Federal Reserve Bank of Minneapolis.

[25] Hall, Robert E., 1978, "Stochastic implications of the life cycle-permanent income hypothesis." Journal of Political Economy, vol. 86, pp. 971-87.

[26] Hall, Robert E., 1988, "Intertemporal substitution in consumption." Journal of Political Economy, vol. 96, pp. 339-357.

[27] Hansen, Lars Peter, and Kenneth Singleton, 1982, "Generalized instrumental variables estimation of nonlinear rational expectations models," Econometrica, vol. 50, pp. 12691288 . 
[28] Hansen, Lars Peter and Singleton, Kenneth J., 1983, "Stochastic consumption, risk aversion, and the temporal behavior of asset returns," Journal of Political Economy vol. 91 , pp. 249-265.

[29] Heaton, John, 1993, "The interaction between time-nonseparable preferences and time aggregation," Econometrica, vol. 61, pp. 353-385.

[30] Heaton, John, 1995, "An empirical investigation of asset pricing with temporally dependent preference specifications," Econometrica, vol. 63, pp. 681-717.

[31] Heaton, John and Lucas, Deborah, 1992, "The effects of incomplete markets and trading costs in a consumption-based asset pricing model," Journal of Economic Dynamics and Control, vol. 16, pp. 601-20.

[32] Jermann, Urban J., 1994, "Asset pricing in production economies", manuscript, Wharton School, University of Pennsylvania.

[33] Judd, Kenneth, 1992, "Projection methods for solving aggregate growth models," Journal of Economic Theory, vol. 58, pp. 410-452.

[34] Kandel, Shmuel and Robert F. Stambaugh, 1991, "Asset returns and intertemporal preferences," Journal of Monetary Economics, vol. 27, pp. 39-71.

[35] Lettau, Martin, and Harald Uhlig, 1995, "Can habit formation be reconciled with business cycle facts?" manuscript, CentER for Economic Research, Tilburg University.

[36] Lucas, Robert E., Jr., 1978, "Asset Prices in an Exchange Economy," Econometrica, vol. 46, pp.1429-1445.

[37] Mankiw, N. Gregory, 1986, "The equity premium and the concentration of aggregate shocks," Journal of Financial Economics, vol. 17, pp. 211-219.

[38] Mehra, Rajnish and Prescott, Edward C., 1985, "The equity premium: a puzzle," Journal of Monetary Economics, vol. 15, pp. 145-161.

[39] Nelson, Charles, and Richard Startz, 1990a, "The distribution of the instrumental variables estimator and its t-ratio when the instrument is a poor one," Journal of Business, vol. 63, part 2, pp. S125-40.

[40] Nelson, Charles, and Richard Startz, 1990b, "Some further results on the exact small sample properties of the instrumental variable estimator," Econometrica, vol. 58, pp. $967-76$.

[41] Nason, James N., 1988, "The equity premium and time-varying risk behavior," Finance and Economics Discussion Paper No. 11 (Board of Governors of the Federal Reserve, Washington, DC).

[42] Reitz, T.A., 1988, "The equity premium: a solution," Journal of Monetary Economics, vol. 22, pp. 117-133. 
[43] Rouwenhorst, K. Geert, 1995, "Asset pricing implications of equilibrium business cycle models," in Tom Cooley, editor, Frontiers of Business Cycle Analysis, Princeton University Press.

[44] Sargent, Thomas J., 1989, "Two models of measurements and the investment accelerator," Journal of Political Economy, vol. 97, pp. 251-287.

[45] Tallarini, Thomas D., Jr., 1994, "Risk-sensitive real business cycles", manuscript, University Chicago.

[46] Tsionas, E.G., 1994, "Asset returns in general equilibrium with scale mixture of normals endowment processes," Unpublished University of Minnesota Ph.D. Dissertation.

[47] Weil, Philippe, 1989, "The equity premium puzzle and the risk-free rate puzzle," Journal of Monetary Economics, vol. 24, pp. 401-421.

[48] Weil, Philippe, 1992, "Comment Cochrane and Hansen," NBER Macroeconomics Annual 1992.

[49] Wilcox, David, 1992, "The construction of US consumption data: some facts and their implications for empirical work," American Economic Review, vol. 82, pp. 922-941. 
Table 1a. Financial Statistics without Leverage

\begin{tabular}{|c|c|c|c|c|c|c|c|c|c|}
\hline & & & & & \multicolumn{4}{|c|}{ Two Sector Economy } \\
\hline & & \multicolumn{2}{|c|}{ Endowment Economy } & \multicolumn{2}{|c|}{ One Sector Economy } & \multicolumn{2}{|c|}{ Full Labor Mobility } & \multicolumn{2}{|c|}{ Limited Labor Mobility } \\
\hline Statistic & Data & No Habit & Habit & No Habit & Habit & No Habit & Habit & No Habit & Habit \\
\hline$r^{e}$ & 7.82 & $\begin{array}{c}1.84 \\
(0.01)\end{array}$ & $\begin{array}{c}8.54 \\
(0.05) \\
\end{array}$ & $\begin{array}{c}1.60 \\
(0.01)\end{array}$ & $\begin{array}{c}1.60 \\
(0.01) \\
\end{array}$ & $\begin{array}{c}1.62 \\
(0.01)\end{array}$ & $\begin{array}{c}1.76 \\
(0.01)\end{array}$ & $\begin{array}{c}1.63 \\
(0.01)\end{array}$ & $\begin{array}{c}4.79 \\
(0.03)\end{array}$ \\
\hline$r^{f}$ & $\begin{array}{c}1.19 \\
(0.81)\end{array}$ & $\begin{array}{c}1.81 \\
(4 \mathrm{e}-3)\end{array}$ & $\begin{array}{c}1.68 \\
(0.12)\end{array}$ & $\begin{array}{c}1.60 \\
(0.01)\end{array}$ & $\begin{array}{c}1.60 \\
(0.01)\end{array}$ & $\begin{array}{c}1.60 \\
(0.01)\end{array}$ & $\begin{array}{c}1.63 \\
(0.01)\end{array}$ & $\begin{array}{c}1.60 \\
(0.01)\end{array}$ & $\begin{array}{c}2.70 \\
(0.06)\end{array}$ \\
\hline$r^{e}-r^{f}$ & $\begin{array}{c}6.63 \\
(1.78) \\
\end{array}$ & $\begin{array}{c}0.02 \\
(0.01) \\
\end{array}$ & $\begin{array}{c}6.86 \\
(0.14) \\
\end{array}$ & $\begin{array}{l}0.001 \\
(1 \mathrm{e}-3) \\
\end{array}$ & $\begin{array}{c}0.001 \\
(6 \mathrm{e}-4) \\
\end{array}$ & $\begin{array}{c}0.02 \\
(0.01) \\
\end{array}$ & $\begin{array}{c}0.13 \\
(0.02) \\
\end{array}$ & $\begin{array}{c}0.03 \\
(0.01) \\
\end{array}$ & $\begin{array}{c}2.10 \\
(0.07) \\
\end{array}$ \\
\hline$\sigma_{r e}$ & 19.53 & $\begin{array}{c}2.32 \\
(0.01) \\
\end{array}$ & $\begin{array}{r}40.0 \\
(0.2) \\
\end{array}$ & $\begin{array}{c}0.40 \\
(0.01) \\
\end{array}$ & $\begin{array}{c}0.37 \\
(4 \mathrm{e}-3) \\
\end{array}$ & $\begin{array}{c}1.84 \\
(0.01)\end{array}$ & $\begin{array}{c}5.76 \\
(0.02) \\
\end{array}$ & $\begin{array}{c}2.52 \\
(0.01) \\
\end{array}$ & $\begin{array}{l}26.4 \\
(0.1) \\
\end{array}$ \\
\hline$\sigma_{r^{\prime}}$ & $\begin{array}{c}5.27 \\
(0.74) \\
\end{array}$ & $\begin{array}{c}0.72 \\
(2 \mathrm{e}-3) \\
\end{array}$ & $\begin{array}{r}15.0 \\
(0.1) \\
\end{array}$ & $\begin{array}{c}0.39 \\
(5 e-3)\end{array}$ & $\begin{array}{c}0.36 \\
(4 \mathrm{e}-3)\end{array}$ & $\begin{array}{c}1.23 \\
(4 \mathrm{e}-3)\end{array}$ & $\begin{array}{c}4.03 \\
(0.01)\end{array}$ & $\begin{array}{c}1.72 \\
(5 e-3)\end{array}$ & $\begin{array}{l}18.2 \\
(0.1)\end{array}$ \\
\hline$\sigma_{r^{e}-r^{\prime}}$ & $\begin{array}{c}19.02 \\
(1.73)\end{array}$ & $\begin{array}{c}2.23 \\
(0.01)\end{array}$ & $\begin{array}{c}36.5 \\
(0.1)\end{array}$ & $\begin{array}{c}0.14 \\
(4 e-4)\end{array}$ & $\begin{array}{c}0.14 \\
(4 \mathrm{e}-3)\end{array}$ & $\begin{array}{c}1.39 \\
(4 \mathrm{e}-3)\end{array}$ & $\begin{array}{c}4.13 \\
(0.01)\end{array}$ & $\begin{array}{c}1.87 \\
(0.01)\end{array}$ & $\begin{array}{l}18.8 \\
(0.1)\end{array}$ \\
\hline$\sigma_{P_{k}}$ & & $\begin{array}{c}0.91 \\
(0.01) \\
\end{array}$ & $\begin{array}{c}9.56 \\
(0.04) \\
\end{array}$ & na & na & $\begin{array}{c}0.30 \\
(1 \mathrm{e}-3) \\
\end{array}$ & $\begin{array}{c}0.97 \\
(1 \mathrm{e}-3) \\
\end{array}$ & $\begin{array}{c}0.42 \\
(1 \mathrm{e}-3) \\
\end{array}$ & $\begin{array}{r}4.27 \\
(0.01) \\
\end{array}$ \\
\hline$\rho\left(Y, P_{k}\right)$ & & $\begin{array}{c}1.00 \\
(1 e-6)\end{array}$ & $\begin{array}{c}0.54 \\
(2 \mathrm{e}-3)\end{array}$ & na & na & $\begin{array}{c}0.31 \\
(2 \mathrm{e}-3)\end{array}$ & $\begin{array}{c}0.07 \\
(1 \mathrm{e}-3)\end{array}$ & $\begin{array}{c}0.25 \\
(2 \mathrm{e}-3)\end{array}$ & $\begin{array}{c}0.25 \\
(1 \mathrm{e}-3)\end{array}$ \\
\hline
\end{tabular}

Notes: (i) The "Data" column contains estimates of the mean and standard deviation of the risk-free return and the equity premium, with standard errors in parentheses over the period 1892-1987 for U.S. data. These estimates are taken from Cecchetti, Lam and Mark (1993). These authors do not standard errors for the return to equity. (ii) All statistics are annualized and in percent terms. (iii) Results for the models are based on 500 replications of sample size 120 and Monte Carlo standard errors are reported in parentheses. The latter are the standard deviation across replications, of the associated statistics, divided by $\sqrt{500}$. (iv) Data results for $\sigma_{P_{k}}$ and $\rho\left(Y, P_{k}\right)$ are reported in Table 1b. (v) 'No Habit' columns correspond to power utility with $\phi=1$, and 'Habit' columns correspond to habit persistence utility with $\phi=1$ and estimated $b, h$. 
Table 1b. Business Cycle Properties of Stock Prices

\begin{tabular}{lllllll}
\multicolumn{7}{l}{ Second Moment Statistics } \\
Industry & \multicolumn{2}{l}{ S\&P 500 } & Dow Jones & \multicolumn{2}{l}{ NYSE } \\
\hline \hline & $\frac{\sigma_{p}}{\sigma_{y}}$ & $\operatorname{corr}(p, y)$ & $\frac{\sigma_{p}}{\sigma_{y}}$ & $\operatorname{corr}(p, y)$ & $\frac{\sigma_{p}}{\sigma_{y}}$ & $\operatorname{corr}(p, y)$ \\
\hline \hline Composite & 4.90 & 0.34 & 4.98 & 0.28 & 4.96 & 0.35 \\
& $(0.49)$ & $(0.09)$ & $(0.52)$ & $(0.10)$ & $(0.49)$ & $(0.09)$ \\
Capital Goods & 5.84 & 0.37 & & & na & na \\
& $(0.54)$ & $(0.09)$ & & & & \\
Utilities & 4.30 & 0.19 & & & 6.49 & 0.26 \\
& $(0.62)$ & $(0.10)$ & & & $(1.40)$ & $(0.09)$ \\
Finance & 6.10 & 0.25 & & & 6.36 & 0.34 \\
& $(0.98)$ & $(0.12)$ & & & $(0.88)$ & $(0.11)$ \\
Industrial & 5.11 & 0.33 & & & 5.38 & 0.29 \\
& $(0.51)$ & $(0.09)$ & & & $(0.71)$ & $(0.13)$ \\
Transportation & 5.76 & 0.12 & & & 7.25 & 0.31 \\
& $(0.83)$ & $(0.15)$ & & & $(1.07)$ & $(0.11)$
\end{tabular}

Notes: (i) Data source - CITIBASE. The sample period is 1947I - 1995I for NYSE Composite, Dow Jones, and 1966I - 1995I for the other NYSE variables. The sample period is 1947I - 1995I for all but two of ti.e S\&P 500 data series. It is 1970I-1995I for S\&P 500 finance and transportation. Data on gross domestic product (GDP) cover the period 1947I - 1995I.

(ii) Statistics - All data were logged, and then Hodrick-Prescott filtered prior to analysis. $\sigma_{p}$ denotes the standard deviation of the (detrended) stock price, $\sigma_{y}$ denotes the standard deviation of output, and $\operatorname{corr}(p, y)$ denotes the correlation between $p$ and $y$. Numbers in parentheses denote the standard errors of $\sigma_{p} / \sigma_{y}$ and $\operatorname{corr}(p, y)$, computed as in Christiano and Eichenbaum (1992). For estimation of the relevant zero-frequency spectral density a Bartlett window, truncated at lag six, was used. 
Table 2. Financial Statistics in the Production Economies, $\gamma=2 / 3$

\begin{tabular}{||c|c|c|c|c|c|c|c||}
\cline { 4 - 8 } \multicolumn{2}{c|}{} & \multicolumn{4}{c||}{ Two Sector Economy } \\
\hline Statistic & Data & No Habit & Habit & No Habit & Habit & No Habit & Habit \\
\hline$r^{e}$ & 7.82 & 1.65 & 1.60 & 1.64 & 1.92 & 1.67 & 7.56 \\
& & $(0.01)$ & $(0.01)$ & $(0.02)$ & $(0.02)$ & $(0.02)$ & $(0.07)$ \\
\hline$r^{e}-r^{f}$ & 6.63 & 0.002 & 0.002 & 0.02 & 0.29 & 0.07 & 4.86 \\
& $(1.78)$ & $(1 \mathrm{e}-3)$ & $(1 \mathrm{e}-3)$ & $(0.01)$ & $(0.03)$ & $(0.01)$ & $(0.13)$ \\
\hline \hline$\sigma_{r^{e}}$ & 19.53 & 0.44 & 0.41 & 2.60 & 7.97 & 3.55 & 37.3 \\
& & $(4 \mathrm{e}-3)$ & $(4 \mathrm{e}-3)$ & $(0.01)$ & $(0.03)$ & $(0.01)$ & $(0.2)$ \\
\hline$\sigma_{r^{e}-r^{f}}$ & 19.02 & 0.24 & 0.23 & 2.31 & 6.89 & 3.12 & 32.2 \\
& $(1.73)$ & $(1 \mathrm{e}-3)$ & $(7 \mathrm{e}-4)$ & $(0.01)$ & $(0.02)$ & $(0.01)$ & $(0.12)$ \\
\hline
\end{tabular}

Notes: See table 1a. 
Table 3: Business Cycle Statistics in the Production Economies

\begin{tabular}{|c|c|c|c|c|c|c|c|}
\hline & & & \multicolumn{4}{|c|}{ Two Sector Economy } \\
\hline & & \multicolumn{2}{|c|}{ One Sector Economy } & \multicolumn{2}{|c|}{ Full Labor Mobility } & \multicolumn{2}{|c|}{ Limited Labor Mobility } \\
\hline Statistic & Data & No Habit & Habit & No Habit & Habit & No Habit & Habit \\
\hline$\sigma_{Y}$ & $\begin{array}{c}2.00 \\
(0.25)\end{array}$ & $\begin{array}{c}1.77 \\
(1 \mathrm{e}-4)\end{array}$ & $\begin{array}{c}1.72 \\
(0.01)\end{array}$ & $\begin{array}{c}1.71 \\
(0.01)\end{array}$ & $\begin{array}{c}1 . \overline{49} \\
(0.01)\end{array}$ & $\begin{array}{c}1.69 \\
(0.01)\end{array}$ & $\begin{array}{c}1.68 \\
(0.001)\end{array}$ \\
\hline$\sigma_{C} / \sigma_{Y}$ & $\begin{array}{c}0.38 \\
(0.04)\end{array}$ & $\begin{array}{c}0.58 \\
(4 e-4)\end{array}$ & $\begin{array}{c}0.40 \\
(2 \mathrm{e}-3)\end{array}$ & $\begin{array}{c}0.66 \\
(1 \mathrm{e}-3)\end{array}$ & $\begin{array}{c}0.34 \\
(2 \mathrm{e}-3)\end{array}$ & $\begin{array}{c}0.70 \\
(1 \mathrm{e}-3)\end{array}$ & $\begin{array}{c}0.68 \\
(1 \mathrm{e}-3)\end{array}$ \\
\hline$\overline{\sigma_{I} / \sigma_{Y}}$ & $\begin{array}{c}2.43 \\
(0.06)\end{array}$ & $\begin{array}{c}1.78 \\
(2 e-3)\end{array}$ & $\begin{array}{c}2.38 \\
(4 \mathrm{e}-3)\end{array}$ & $\begin{array}{c}1.67 \\
(2 \mathrm{e}-3)\end{array}$ & $\begin{array}{c}2.46 \\
(4 \mathrm{e}-3)\end{array}$ & $\begin{array}{c}1.70 \\
(2 \mathrm{e}-3)\end{array}$ & $\begin{array}{c}1.74 \\
(2 \mathrm{e}-3)\end{array}$ \\
\hline$\sigma_{H} / \sigma_{Y}$ & $\begin{array}{c}0.83 \\
(0.07) \\
\end{array}$ & $\begin{array}{c}0.29 \\
(2 \mathrm{e}-3) \\
\end{array}$ & $\begin{array}{c}0.23 \\
(2 \mathrm{e}-4) \\
\end{array}$ & $\begin{array}{c}0.26 \\
(2 \mathrm{e}-4)\end{array}$ & $\begin{array}{c}0.46 \\
(3 e-3)\end{array}$ & $\begin{array}{c}0.29 \\
(3 e-4)\end{array}$ & $\begin{array}{c}0.29 \\
(3 e-4)\end{array}$ \\
\hline$\overline{\rho(Y, C)}$ & $\begin{array}{c}0.79 \\
(0.06) \\
\end{array}$ & $\begin{array}{c}0.99 \\
(1 \mathrm{e}-3)\end{array}$ & $\begin{array}{c}0.66 \\
(1 \mathrm{e}-3)\end{array}$ & $\begin{array}{c}0.97 \\
(2 \mathrm{e}-4)\end{array}$ & $\begin{array}{c}0.62 \\
(1 \mathrm{e}-3)\end{array}$ & $\begin{array}{c}0.93 \\
(5 e-4)\end{array}$ & $\begin{array}{c}0.92 \\
(6 \mathrm{e}-4)\end{array}$ \\
\hline$\rho(Y, I)$ & $\begin{array}{c}0.96 \\
(0.01)\end{array}$ & $\begin{array}{c}1.00 \\
(4 e-5)\end{array}$ & $\begin{array}{c}0.97 \\
(2 \mathrm{e}-4)\end{array}$ & $\begin{array}{c}0.98 \\
(2 \mathrm{e}-4)\end{array}$ & $\begin{array}{c}0.98 \\
(2 \mathrm{e}-4)\end{array}$ & $\begin{array}{c}0.96 \\
(5 e-4)\end{array}$ & $\begin{array}{c}0.96 \\
(5 \mathrm{e}-4)\end{array}$ \\
\hline$\overline{\rho(Y, H)}$ & $\begin{array}{c}0.82 \\
(0.05) \\
\end{array}$ & $\begin{array}{c}0.99 \\
(2 \mathrm{e}-3) \\
\end{array}$ & $\begin{array}{c}0.99 \\
(2 e-4) \\
\end{array}$ & $\begin{array}{c}0.93 \\
(2 \mathrm{e}-4) \\
\end{array}$ & $\begin{array}{c}0.23 \\
(3 e-3) \\
\end{array}$ & $\begin{array}{c}0.81 \\
(2 \mathrm{e}-3) \\
\end{array}$ & $\begin{array}{c}0.80 \\
(2 \mathrm{e}-3) \\
\end{array}$ \\
\hline$\rho\left(Y, H_{C}\right)$ & $\begin{array}{c}0.72 \\
(0.08)\end{array}$ & $\begin{array}{l}-0.97 \\
(2 \mathrm{e}-3)\end{array}$ & $\begin{array}{c}-0.88 \\
(1 \mathrm{e}-3)\end{array}$ & $\begin{array}{l}-0.99 \\
(2 e-4)\end{array}$ & $\begin{array}{c}-0.66 \\
(1 \mathrm{e}-3)\end{array}$ & $\begin{array}{l}-0.80 \\
(2 \mathrm{e}-3)\end{array}$ & $\begin{array}{c}-0.80 \\
(2 \mathrm{e}-3)\end{array}$ \\
\hline$\rho\left(Y, H_{K}\right)$ & $\begin{array}{c}0.86 \\
(0.04) \\
\end{array}$ & $\begin{array}{c}0.98 \\
(2 \mathrm{e}-3)\end{array}$ & $\begin{array}{c}0.94 \\
(6 \mathrm{e}-4)\end{array}$ & $\begin{array}{c}0.95 \\
(1 \mathrm{e}-3)\end{array}$ & $\begin{array}{c}0.95 \\
(1 \mathrm{e}-3)\end{array}$ & $\begin{array}{c}0.81 \\
(2 \mathrm{e}-3)\end{array}$ & $\begin{array}{c}0.80 \\
(2 \mathrm{e}-3)\end{array}$ \\
\hline $\operatorname{FREQ}\left(I_{C} \leq 0\right)$ & & $\begin{array}{c}0.02 \\
(0.01)\end{array}$ & $\begin{array}{c}2.08 \\
(0.06)\end{array}$ & 0 & $\begin{array}{c}0.85 \\
(0.04)\end{array}$ & 0 & 0 \\
\hline $\operatorname{FREQ}\left(I_{K} \leq 0\right)$ & & $\begin{array}{c}1.65 \\
(0.07) \\
\end{array}$ & $\begin{array}{c}11.3 \\
(0.2)\end{array}$ & $\begin{array}{c}0.98 \\
(0.05)\end{array}$ & $\begin{array}{c}9.40 \\
(0.14)\end{array}$ & $\begin{array}{c}1.07 \\
(0.05)\end{array}$ & $\begin{array}{c}1.71 \\
(0.07)\end{array}$ \\
\hline
\end{tabular}


Notes to Table 3: (i) In the "Data" column are reported estimates of the relevant statistic and in parenthesis standard errors of the estimates from U.S. data 1964:1-1988:2. The standard errors are based on the GMM procedure described in Christiano and Eichenbaum (1992). With the exception of the sectoral hours data, all the data used for these estimates is from an updated version of the Christiano (1988) database, compiled by Fisher (1994). The sectoral hours data are from Citibase. For the consumption sector we used two alternative measures: an index of hours worked in the service sector (Citibase series LWHPX) and an index of hours worked in the nondurable manufacturing sector (LWHNX). The point estimate and standard error for the correlation of consumption sector hours worked with output based on LWHPX are reported in the table. The analogours point estimate and standard error based on LWHNX are $0.83(0.05)$; (ii) With the exception of the correlations and the relative volatilities, all the statistics are reported in per cent terms; (iii) Results for the model are based on 500 replications of sample size 120 and Monte Carlo standard errors are reported in parentheses. 
Table 4: Other Business Cycle Statistics for the Limited Labor Model With Habit

\begin{tabular}{|lcccc|}
\cline { 3 - 5 } \multicolumn{1}{l}{} & \multicolumn{3}{c|}{$\begin{array}{l}\text { Instrumental Variables Estimates } \\
\Delta C_{t}=\mu+\lambda \Delta Y_{t}+\theta r_{t}+\varepsilon_{t}\end{array}$} \\
\hline US data & $\rho$ & $\lambda$ & $\theta$ & $R_{\Delta y}^{2}$ \\
\hline \multirow{3}{*}{ Model Results } & 0.37 & 0.47 & 0.089 & 0.046 \\
& $(0.07)$ & & & \\
& 0.20 & 0.98 & 0.034 & 0.036 \\
& $(4 \mathrm{e}-3)$ & $(0.01)$ & $(1 \mathrm{e}-4)$ & $(2 \mathrm{e}-3)$
\end{tabular}

Notes:

(i) $\Delta x_{t} \equiv \log \left(x_{t}\right)-\log \left(x_{t-1}\right)$. US data estimates for $\lambda, \theta, R_{\Delta y}^{2}$ are taken from Campbell and Mankiw (1989). The estimate of $\rho$, the first order autocorrelation of $\Delta Y_{t}$, is based on logged US real GDP growth covering the period 1947:I-1995:I. The standard error for this statistic is reported in parentheses, and is computed using the procedure described in the note to Table 1b. 'Model Results' entries represent the indicated statistic based on 120 simulated observations from the limited labor model with habit, averaged across 500 replications. Numbers in parentheses are the associated Monte Carlo standard errors.

(ii) $\rho \sim$ autocorrelation of consumption growth, $R_{\Delta y}^{2} \sim R$-bar squared of regression of $\Delta y_{t}$ on instruments.

(iii) Instruments: US data - $\left\{\Delta c_{t-2}, \ldots, \Delta c_{t-4}, r_{t-2}, \ldots, r_{t-4}\right\}$, Model simulations - $\left\{\Delta c_{t-1}, \ldots, \Delta c_{t-3}, r_{t-1}, \ldots, r_{t-3}\right\}$.

(iv) Simulation results based on $r_{t}=r_{t-1}^{f}$. We also performed the simulations with $r_{t}=r_{t}^{e}$, and obtained results essentially the same as those reported here. 
Figure 1: Exchange economy, power utility




Figure 2: Exchange economy - impact of habit persistence parameters, $h$ and $b$

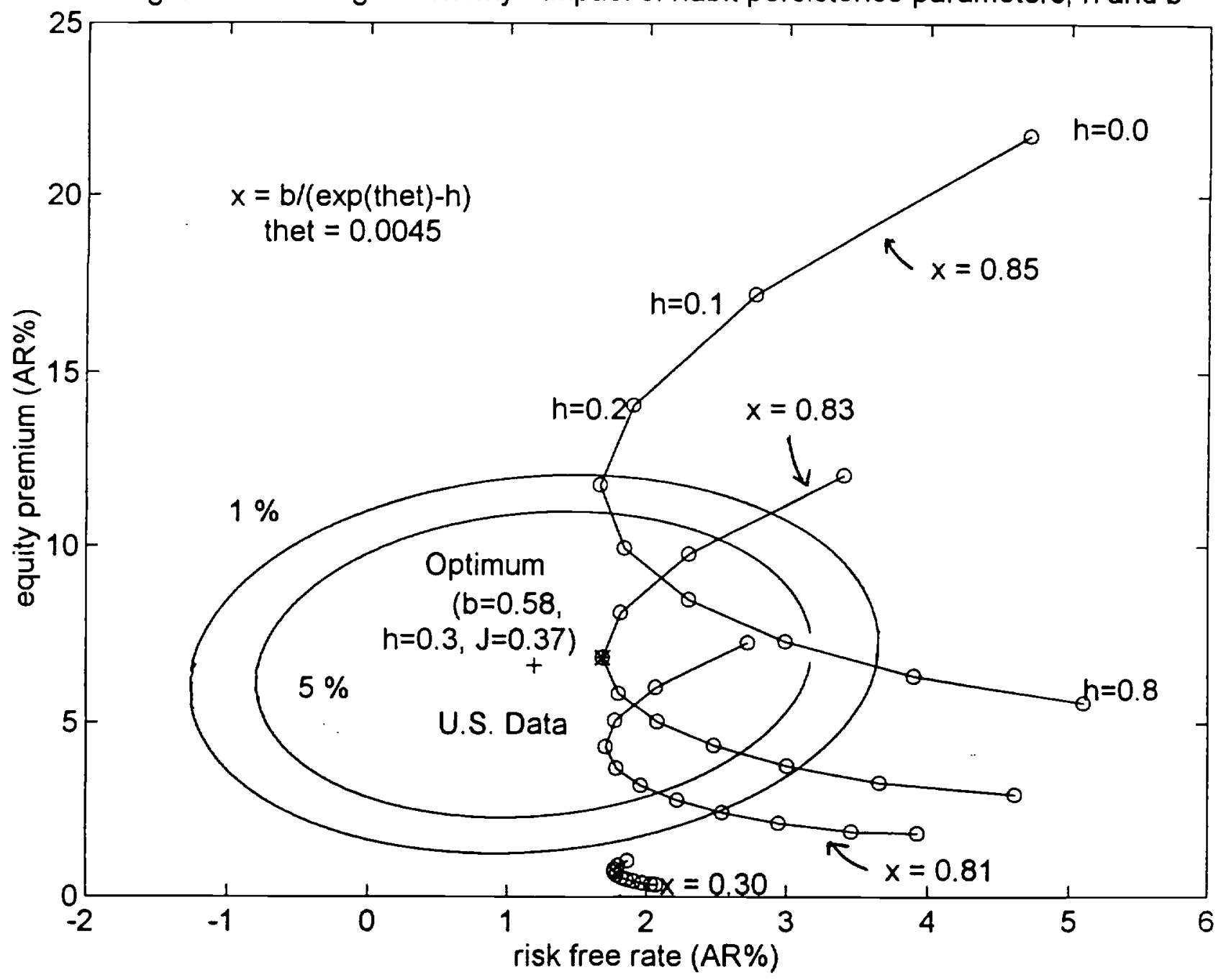


Figure 3: One-sector production economy

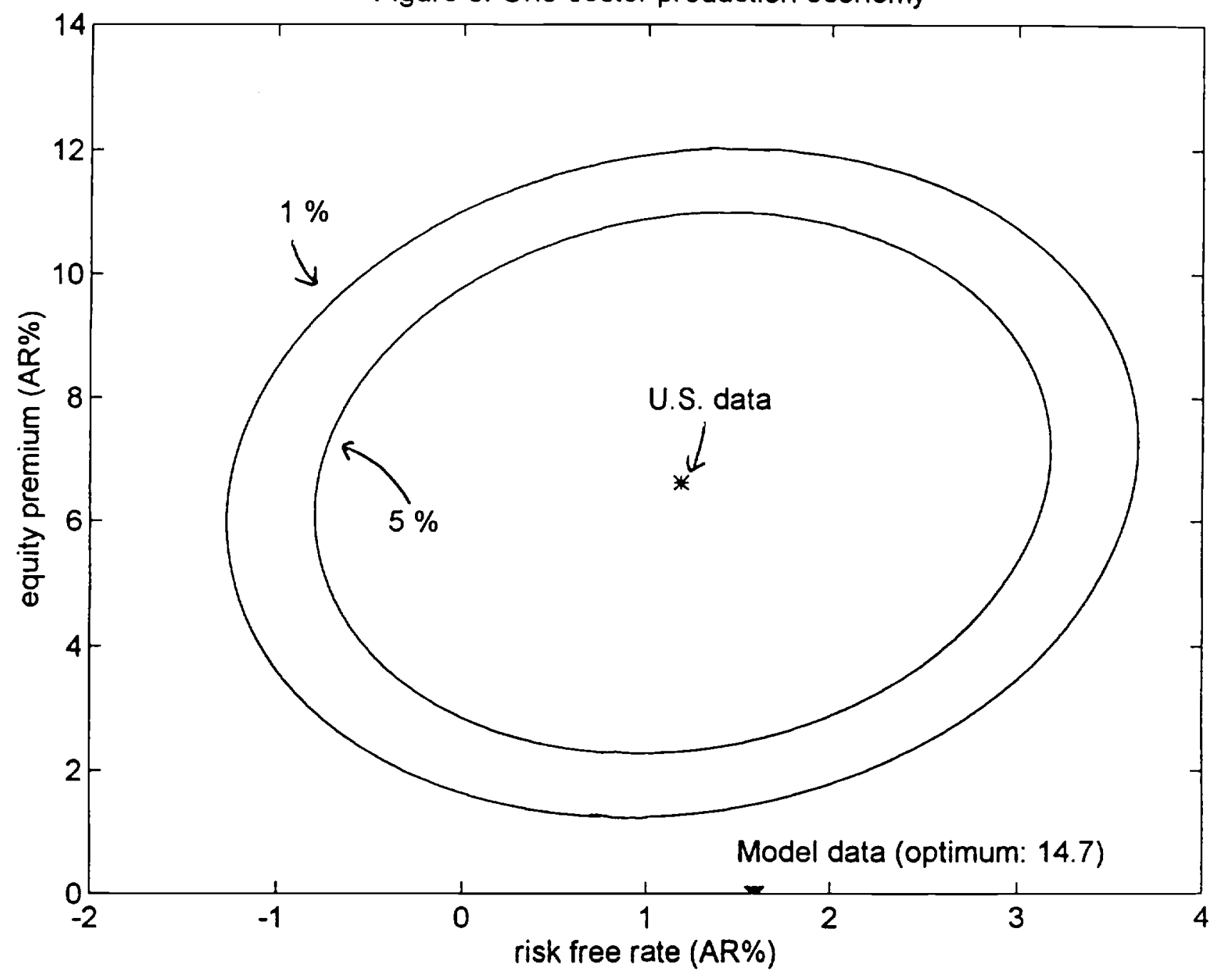


Figure 40: Response of $\mathrm{C}$

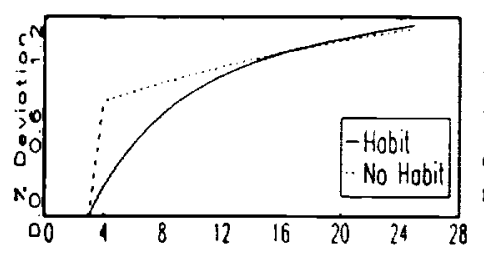

Figure 4b: Response of 1

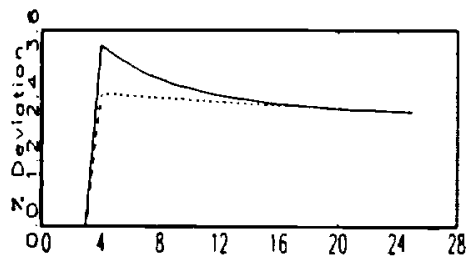

Figure 4c: Response of $\mathrm{h}$
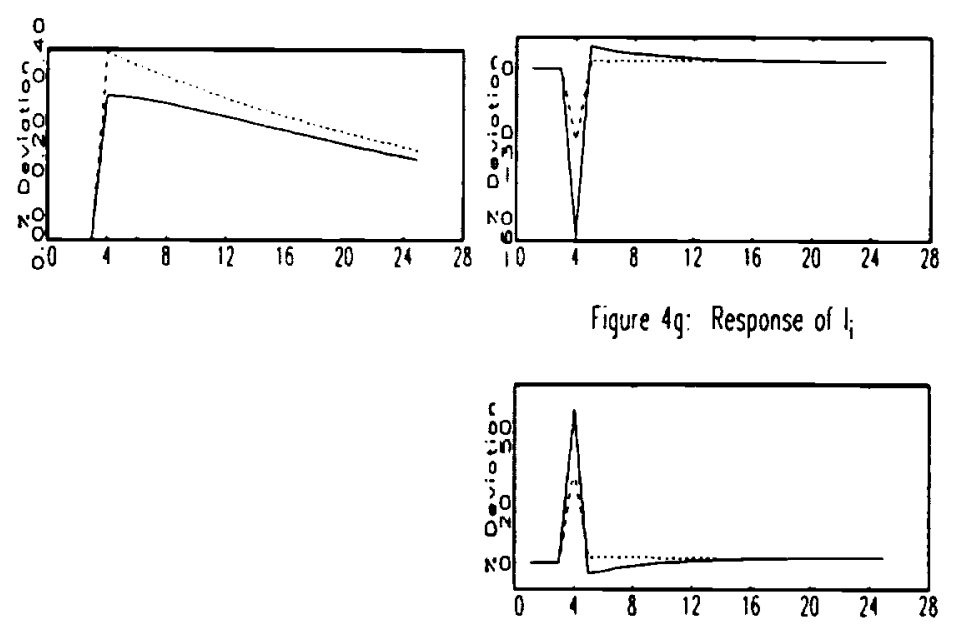

Figure 4: Impulse Response Functions for One-Sector Models 
Figure 5: Two sector economy, full labor mobility

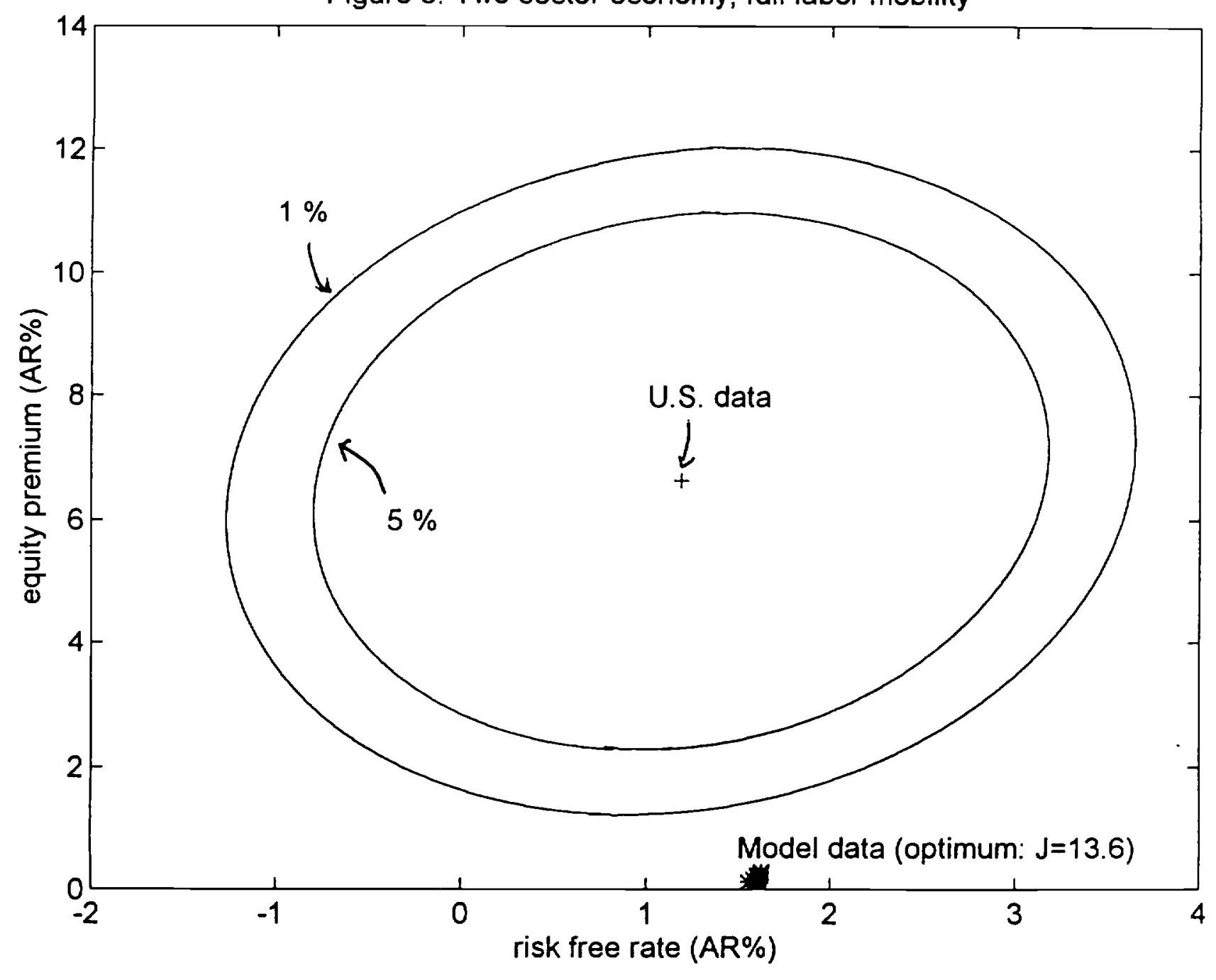


Figure 6: Two-sector production economy with limited labor mobility

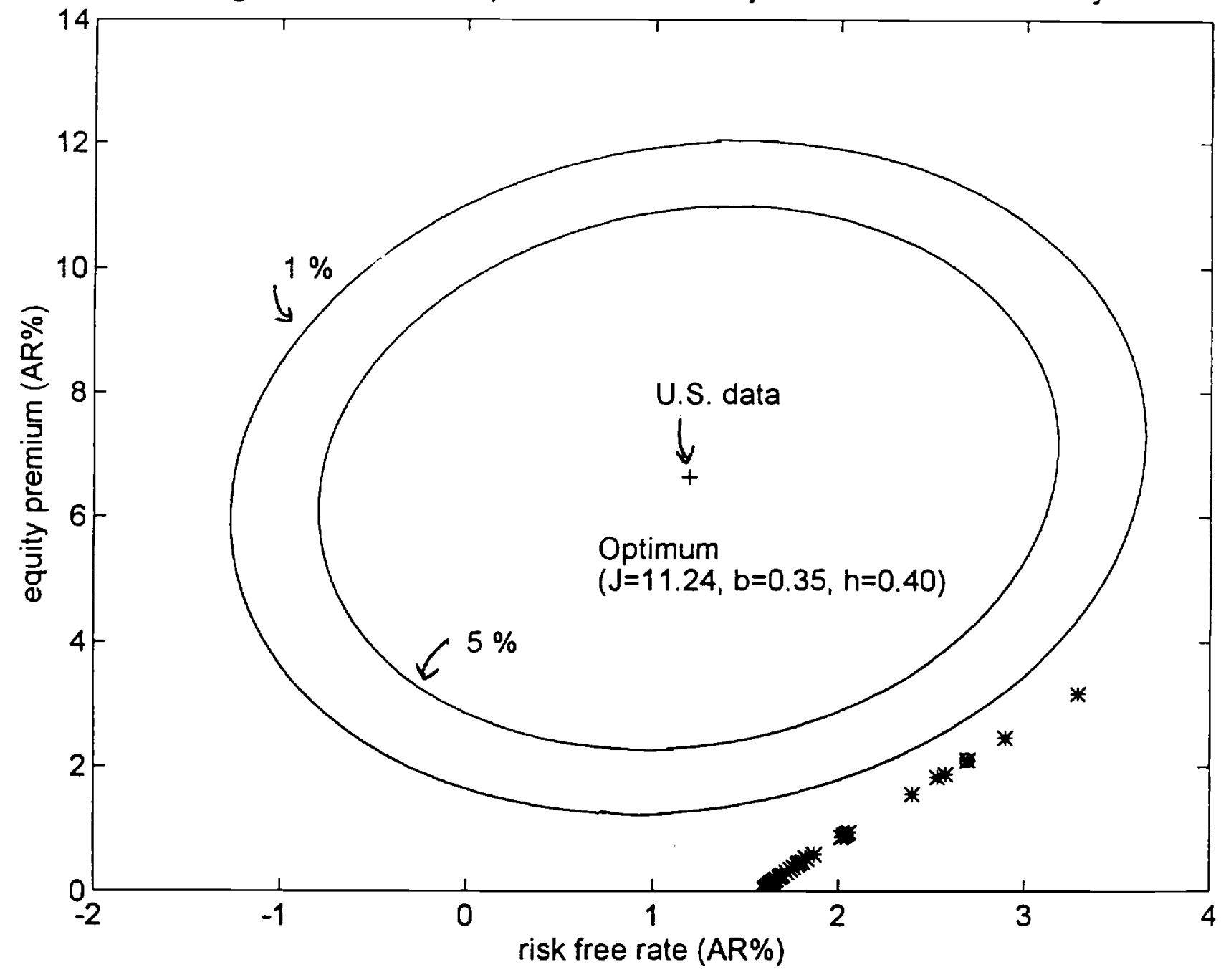


Fique 70: Response of $\mathrm{C}$

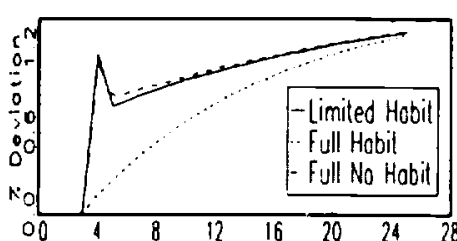

Fiqure 76. Response of 1

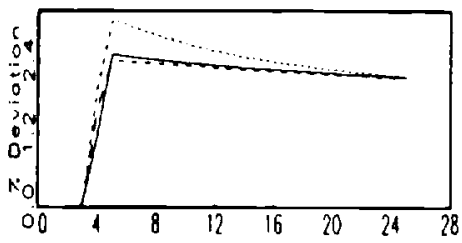

Figure 7c: Response of h

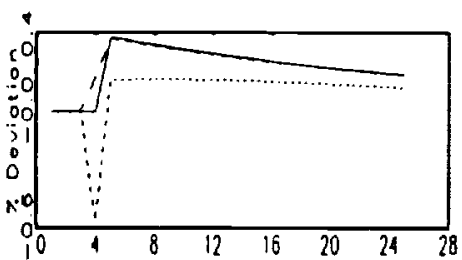

figure 7d: Response ol $\mathrm{P}_{\mathrm{k}}$

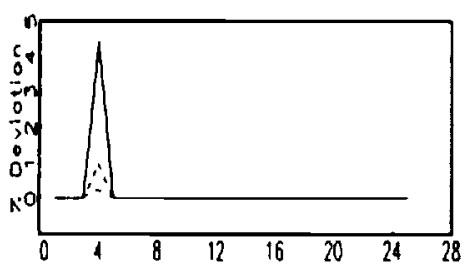

Figure 7e: Response of $h_{c}$

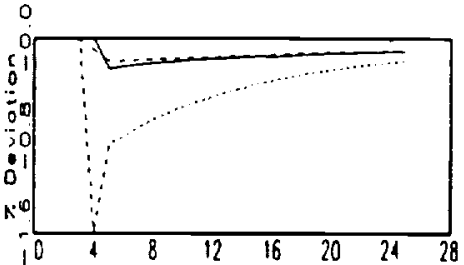

Figure 7f: Response of $h_{\text {i }}$
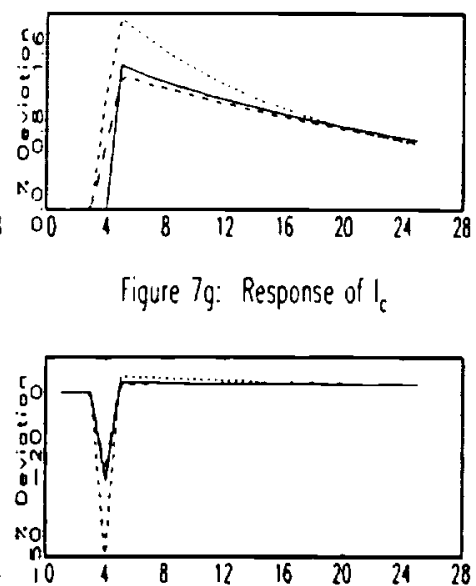

Figure 7h: Response of !

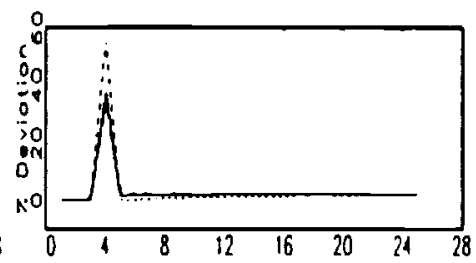

Figure 7: Impulse Response Functions for Two-Sector Models 
Figure 8: Two-sector production economy with limited labor mobility and leverage

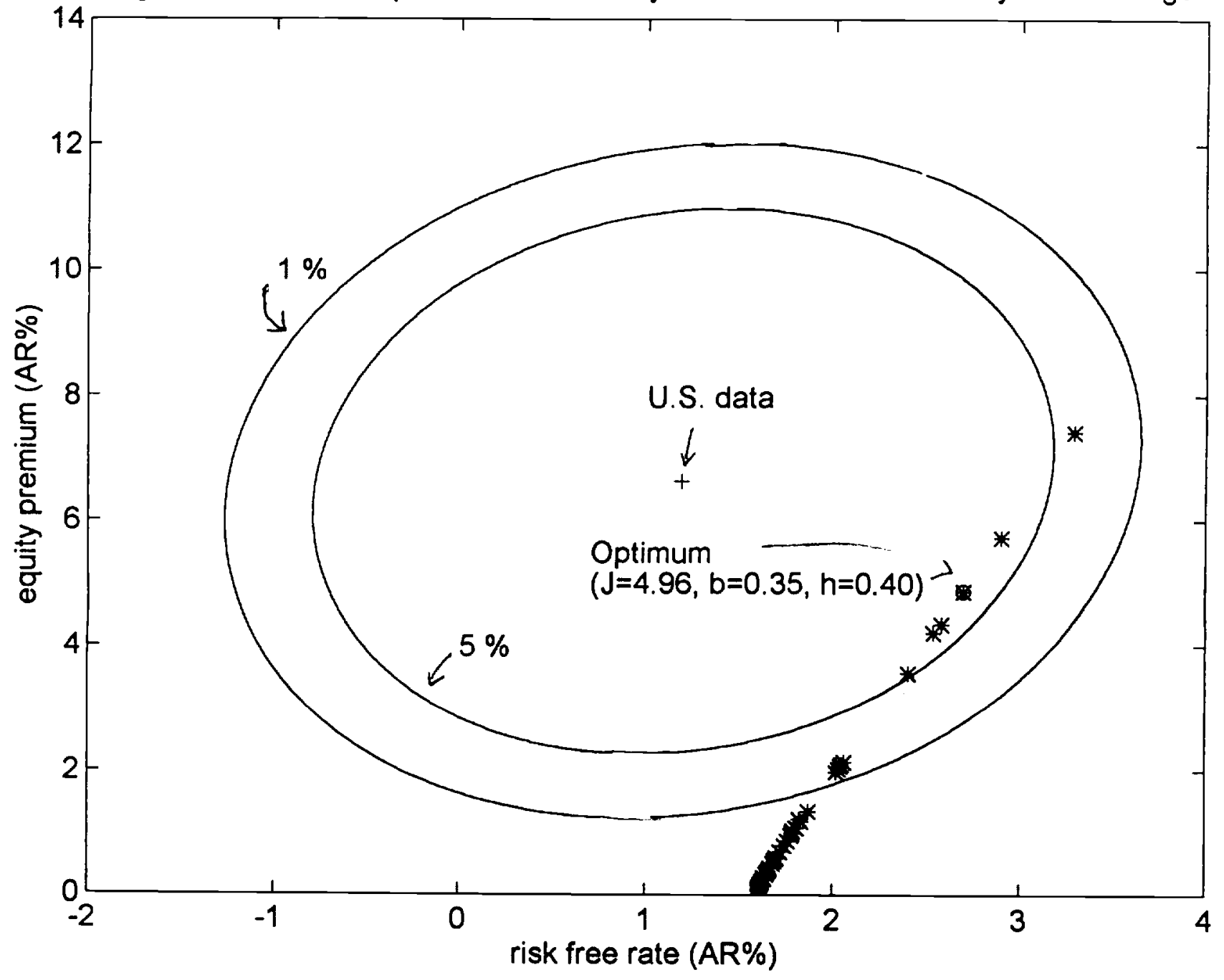

